\title{
Triumphatores ex Hispania (36-26 a.C.) según los Fasti Triumphales
}

\author{
Sabino Perea YéBEnes \\ Universidad de Murcia \\ sperea@um.es
}

\section{RESUMEN}

Realizamos un estudio histórico-prosopográfico de los generales romanos que celebraron triunfos entre los años 36 y 26/25 a.C. por sus conquistas y guerras en el Noroeste de Hispania. La frecuencia de estos triunfos revela la importancia de Hispania en la estrategia militar de Octavio-Augusto, como demuestra su presencia en el escenario bélico, y el encargo posterior a Agripa para "cerrar definitivamente el conflicto". Este, sin embargo, con más méritos militares que todos los que le habían precedido en la guerra del noroeste hispano, renunció a la celebración del triunfo. El concepto de triumphus había cambiado, y de hecho pronto cesan las inscriptiones en los Fasti Triumphales, quedando la ceremonia como un privilegio exclusivo del príncipe.

Palabras clave: Conquista del NO de Hispania. Generales romanos. Prosopografía. Triumphus. Roma. Augusto. Agripa.

\section{Triumphatores ex Hispania (36-26 a.C.) in the Fasti Triumphales}

\begin{abstract}
This paper shows the list of the Roman generals who participated in the last episodes of the wars waged in the Hispanic Northwest and who celebrated triumphs in Rome between 36 and 26/25 BC. The frequency of these triumphus had shown the importance of Hispania in the military strategy of Octavian-Augustus, as evidenced by their presence in the theater of war, and the subsequent assignment to Agrippa to "close down the conflict". Agrippa, however, with more military merits than all who had preceded him in the war of the Spanish northwest, rejects the celebration of the triumph. The triumphus concept had changed: soon cease the inscriptiones in the Fasti-list in Rome, leaving the ceremony as an exclusive privilege of the princeps.
\end{abstract}

Key Words: Conquest of NW Spain. Roman commanders. Prosopography. Triumphus. Rome. Augustus. Agrippa. 
Estudiamos aquí brevemente la prosopografía de los generales romanos que celebraron triunfos entre los años 36 y 25 a.C., merced a sus victorias sobre los indómitos pueblos del noroeste de la Península Ibérica, a partir varias listas de Fasti (Triumphales, Capitolini, etc.) conservados, aunque ninguno en su integridad, en distintos museos, siendo el documento más importante el conservado en la "sala de la loba" de los Museos Capitolinos de Roma. ${ }^{1}$ Este repaso puramente formal nos permite reflexionar sobre la importancia de Hispania - de la conquista total de Hispania- en el conjunto de los territorios que estaban siendo anexionados, a distinto ritmo y con distinto éxito, entre los años 36 y 25. Los termini temporales tienen sentido pleno, al menos en Hispania: el 36 es la fecha del primer triumphus celebrado en Roma (al menos registrado en los documentos oficiales, y por tanto en los Fasti) en relación con la presencia de tropas romanas en el noroeste hispano. La segunda fecha coincide con la cita doble, para los años 26 y 25, en los Fasti Feriarum Latinarum de la presencia de Augusto en este escenario bélico ([Imp. Caesar in] Hispania fuit). En nuestro estudio también damos importancia a dos circunstancias: el triple triunfo de Octavio el año 29; y las renuncias de Agripa a celebrar los triunfos que le correspondían dejando ese honor, indirectamente, a Octavio-Augusto.

1 Sobre el triunfo romano, las fuentes epigráficas son fundamentales, y entre ellas las ediciones de los Fasti Triumphales, aún no superadas, debidas a PAIS 1920 (edición y aparato fotográfico impresionante), y DeGrassi 1947 (edición en la que hay que tener en cuenta las anotaciones de L. Ross Taylor en Classical Philology, 45/2, 1950, pp. 84-95); Degrassi 1954. Buenas imágenes de los Fasti Capitolini, exhibidos ahora en la llamada "sala de la loba" de los museos capitolinos de Roma, pueden verse en Giustozzi 2006, y sobre todo en el libro de LA ROCCA - TORTORELla 2008, absolutamente imprescindible sobre el tema. Los textos históricos fundamentales sobre Octavio-Augusto en los años que aquí estamos estudiando, pueden encontrarse

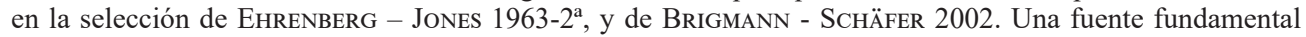
para la historia de Augusto son sus Res Gestae, de las que hay numerosas ediciones. He manejado con gusto la humilde pero inteligente edición de CANALI 1982, la clásica de GAGÉ 1935, con buenos comentarios, y una en español, reciente, que reúne los avances anteriores, y aporta una nueva traducción excelente, DEL Cerro Calderón 2010, donde se comentan los fragmentos de $R G$ relativos a los triunfos de Octavio. Sobre la naturaleza de esta obra: Ramage 1987. Sobre el significado político y religioso del triumphus romano se han escrito buenas obras, cuya lectura, complementaria, nos da un panorama completo, a saber: BARINI 1952 (obra muy crítica con las celebraciones triunfales en época imperial, época en la que habría perdido su esencia); KÜNZ 1988 (solo época imperial, de los Flavios en adelante); AULIARD 2001, con especial atención a los aspectos institucionales; ITGENSHORST 2005 (solamente trata el triumphus de época republicana; este trabajo se complementa con otro de la misma autora, 2004, 436-458); más importante aún, imprescindible: BASTIEN 2007, libro del que interesan especialmente, para nuestro propósito, las pp. 59-66 sobre la discusión de los monumentos augusteos que acogieron o pudieron acoger las lista de los Fasti Triumphales; la lista de los triunfadores (desde el año 339 al 19 a.C.), 403-415; sobre Octavio-Augusto, index sub voce, p. 457. Finalmente, BEARD 2009, obra más ligera, con más adorno literario y descuido de fuentes (véase la recensión de GonZÁlez Salinero 2009). Más generales y desvaídos son los capítulos dedicados al triunfo romano en la obra de Spalinger - Armstrong 2013. Sobre el tema de las aclamaciones militares, las ovationes y el triumphus dediqué hace bastantes años un estudio a cuya lectura igualmente invito: PEREA YéBENEs 20022003, 141-176. Sobre algunas connotaciones antropológicas, rituales, simbólicas y "mágicas" del triunfo, RÜPKE 2006, 251-289; CIERI VIA 2008. Sobre la ceremonia triunfal como espectáculo: MAIURO 2008; BEARD 2008; Schiesaro 2008; Lo Monaco 2008. Para Hispania, interesa el artículo de Amela Valverde 2006, 49-61 (coincide parcialmente con el arco temporal tratado en el presente estudio, pero su enfoque es muy diferente; nos han interesado especialmente las páginas 53-57, que tratan sobre la guerra astur-cántabra entre los años 29-27. El título y el enfoque de dicho estudio adolece de un defecto de fondo: se presentan como "republicanos" los triunfos de varios legados-procónsules entre el 36 y el 27 cuando en realidad sabemos que son "hombres de Octavio"). 


\section{Los triumphatores ex hispania (36-26 a.C.) ${ }^{2}$}

\section{Año 36. Cn. Domitius M. f. M. n. Calvinus procos. ex Hispania XVI k. sextil}

Fue un hombre de extensa y brillante carrera política; tras algunas dudas iniciales, se mostró siempre un cesariano convencido, ayudando a César en sus guerras contra Pompeyo. ${ }^{3}$ Tras la muerte del dictador se convirtió en un poderoso aliado de Octa-

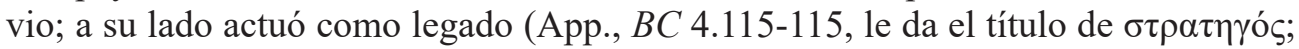
Plut., Brut. 47.4; Cass. Dio, 47.47.4). Intentó apoyar la ofensiva de Filipos en el 42

2 La conquista militar del NO hispano ha sido objeto de estudio para muchos historiadores de Augusto. Para mí los que más datos de interés aportan, para la perspectiva aquí estudiada, son, por fecha de publicación: Magie 1929; Syme 1934, del que interesan especialmente las pp. 301-302, sobre los legados de Augusto en Hispania; y pp. 305-308, sobre P. Carisio, pp. 315-316 con el apéndice prosopográfico de los gobernadores de la Citerior y de Lusitania entre los años 27-17); Horrent 1953, 279-290 (hace una crítica al trabajo de MAGIE y analiza las fuentes latinas, Floro y Orosio, para aclarar algunos episodios concretos del año 26 en el frente cántabro, contrastándolos con el relato de Dión; en el mismo sentido, vid. el reciente estudio de RicH 2009, 145-172. Sigue siendo útil la consulta del libro de SCHUlten 1962, y SCHMitThenNer 1962, 29-85; BRANCATi 1963; Forni 1970; Jones 1976. En general sobre Augusto e Hispania, téngase en cuenta también el viejo estudio de Rodríguez Colmenero 1979, claramente superado en muchos aspectos. Más recientes son los capítulos-síntesis de Montenegro DuQue 1978, 253-285, ID. 1982, 169-192; SANTOS YANGUAS 1982; Peralta Labrador 2000; Perea Yébenes 2008, 120-131. En la obra colectiva coordinada por Aja SÁNCHEZ (2008), además de nuestro trabajo, presenta otros interesante de historia militar romana, centrados más bien en estudios arqueológicos que en buena parte completan y/o enmiendan las hipótesis de Peralta Labrador, en la obra citada antes, especialmente a propósito de los movimientos tácticos de las tropas romanas y de la ubicación y datación de algunos campamentos; RicH 2009, 145-172 (visión general, con una bibliografía de autores españoles anticuada; presta nula atención a los triumphus ex Hispania). El repertorio de fuentes principal para el período sigue siendo, a pesar del año de su publicación, SCHULTEN 1940, obra que precisa una actualización urgente. Sobre los generales de Augusto que intervinieron en Hispania y recibieron triunfos: AlFöLDY 1969; así como nuestro trabajo citado antes, PEREA YÉBENES 2008; con más referencias prosopográficas. En especial sobre los aquí citados generales de Octavio-Augusto en Hispania: Evans, 1987. Para las luchas políticas en Hispania tras la muerte de César y el año 30, es fundamental: Amela VALVERde 2009. Sobre la prosopografía en este estudio: fundamental es la obra de BrougThON $M R R, 1952$, con el suplemento publicado en New York, 1960. Como se observa en el título, el autor sitúa el final de la República en el año de Actium, pero para los años 36-31 su consulta nos ha resultado utilísima. Se utiliza, para los primeros años del Principado, el repertorio $P I R^{2}$ (E. GroAg - A. SteIN 1936 ss.), aunque, como bien sabemos, las noticias que aportan sobre cada personaje son magras en extremo, están bien documentadas con las referencias epigráficas. Para nuestro propósito aquí son suficientes. Sobre algunos Balbos de Gades citados aquí ocasionalmente como "confidentes de César", me refiero naturalmente al conocido trabajo de RodríGuez Neila 1992 (2ª). Para los últimos años de la República, incluidos en este estudio, y los gobernadores provinciales hispanos, SALINAS DE FRÍAS 1996; Roldán Hervás - Wulf Alonso 2001.

3 Había pisado el campo de batalla como legado de Valerius Flaccus en Asia (Cic., Flacc. 31 y 68) el año 62; como tribuno mostró inicialmente su oposición a los triunviros César, Pompeyo y Craso (Cic., Sest. 113; Cass. Dio, 38.6.1); pretor (Cic., QF 2.3.6), y iudex quaestionis en el 56 (Cic., Cael. 32 y 70-72); cónsul en el 53. Vuelve al escenario bélico a Asia Menor en el 48 (Bell. Alex. 34.5). Luchó en el bando cesariano durante las luchas civiles que éste mantuvo con Pompeyo en Grecia; resultó victorioso su encuentro contra los pompeyanos junto al río Haliacmon, en abril del 48 a.C. (Caes., BC III 31.33-34 y 36-37); y poco después en el asedio de Gomphi, hoy Palaeo-Apiskopi, ruinas en las cercanías de Musákion, el 31 de julio de 48 a.C. (Caes., BC III 79; Plut., Caes. 41; App., BC II 64; Floro, II 13 (IV 2.41); Cass. Dio, XLI 51.4-5); y a final de ese mismo año, el 28 de diciembre, combatió exitosamente contra Farnaces II, rey del Bósforo Cimerio, y Deiotaro, en Nicopolis (Bell. Alex. 34-41; Livio, Per. CXII 8; Suet., Caes. 36; Plut., Caes. 50; App., BC II 91; Cass. Dio, XLII 46.1-3); y en Farsalo (Caes., BC 3.89.3; Plut., Pomp. 69.1; Caes. 44.1; App., BC 2.76). En el 48 vuelve a Roma para incorporarse a la campaña Africana de César (Bell. Afr. 86.3; 93.1; cf. Cic., Deiot. 25). 
aportando una flotilla de barcos, que fue destruida por los enemigos en la travesía del Jónico. Con todo, seguía teniendo la confianza Octavio, y obtiene el año 40 ejerce su segundo consulado. Al año siguiente Octavio le envía como procónsul a Hispania, donde somete una rebelión de los Cerretani, pueblo ibero de la zona de los Pirineos (Vell. Pat., 2.78.3; Cass. Dio, 48.42.1-3). ${ }^{4}$ Este proconsulado indica la gran confianza que seguía teniendo Octavio hacia Calvinus a pesar de algunos reveses políticos y militares, por el hecho de que fue un aliado fiel desde el principio a la causa de Octavio, como antes lo había sido de César. El trienio 39-36 se saldó exitosamente para Calvino con la celebración del triumphus (Act. Tr., año 36, Degrassi, p. 86-87 y 568; CIL II, 6186). Pero el destino hispano" también significó en cierto modo un alejamiento de Calvino de los escenarios bélicos más calientes de esa época tan convulsa. ${ }^{5}$ Interesa especialmente la noticia de Cass. Dio, 48.42.4, relativa al triunfo de

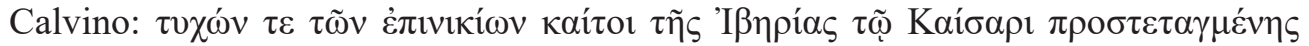

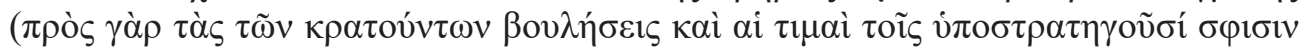

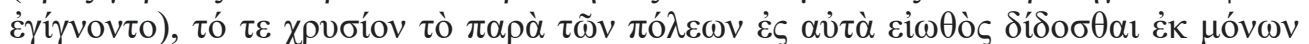

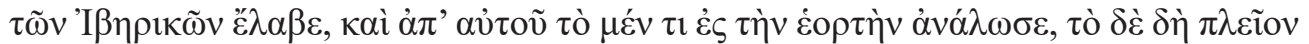

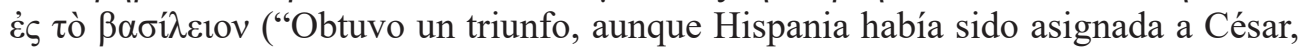
pues, por deseo de los que ostentaban el mando, los honores también recaían en los lugartenientes, y únicamente de las ciudades hispanas recibió el oro que, según la

4 Cass Dio, 48.42.1-3: "Y en ese tiempo ocurrió también en Hispania la revuelta de los cerretanos

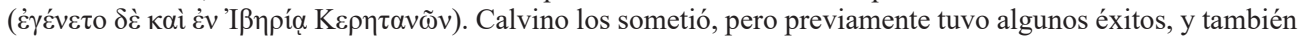
fracasos a causa de su lugarteniente, que fue emboscado por los bárbaros y abandonado por sus soldados

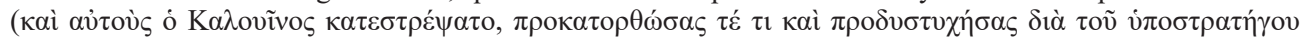

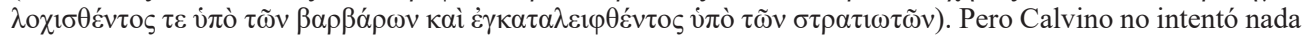
contra los enemigos hasta haber castigado a esos soldados. Los convocó con cierto pretexto y los rodeó con el resto del ejército; apartó dos centurias y ejecutó por sorteo a uno de cada diez, y aplicó este castigo a muchos

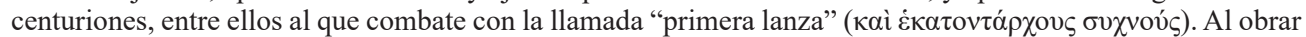
así Calvino, como antes había hecho Marco Craso, adquirió renombre por la forma de mantener la disciplina militar, y entonces marchó contra los enemigos y los sometió sin grandes dificultades".

5 Basta mencionar algunos acontecimientos del año 36 para hacernos una idea. En Siria, Antonio redistribuye el territorio conquistador a los reyes en Capadocia, Ponto y Cilicia (Strab., 12.534; Plut., Ant. 36.2-7; Cass. Dio, 49.32); poco después invade Media (Cass. Dio, 49.24.2-25.2). En Sicilia, Octavio y Lépido preparan un ataque conjunto (App., $B C$ 5.96-98); Agripa derrota a Demochares, almirante de Sex. Pompeyo cerca de Mylae (Vell., 2.789.4; App., BC 5.105-108; Cass. Dio, 49.2.1-4.4); en el verano de ese año Octavio es derrotado por Sex. Pompeyo cerca de Tauromenio (Suet., Aug. 16.3 y 96.2; App., BC 5.109; Cass. Dio, 49.5.1-7.6 y 50.19.2). En Persia, dos legiones romanas, mandadas por Oppius Statianus, son destruidas por los partos (Vell., 2.82.2 y 91.1; Plut., Ant. 38.5-6; Flor., 2.20.3; Cass. Dio, 49.25.4-26.2; 44.2; 53.33.2); el 2 de septiembre, Octavio inflige una derrota decisiva a Sexto Pompeyo en Nauloco (Vell., 2.79.5; Suet., Aug. 16.2; Flor., 2.18.7; App., BC 5.118-121; Cass. Dio, 49.8.1-11.1). Ese mismo mes, Lépido abandona su ejército, y Octavio asume sus poderes triunvirales (Tac., Ann. 1.9-10; Plut., Ant. 55.3-4; Suet., Aug. 16.4; App., BC 5.122-126), Cass. Dio, 49.11.2-12.3); Octavio premia a sus soldados (Vell., 1.81.1-2; Plin., HN 2.24; App., BC 5.127-129; Cass. Dio, 49.13.1-14.5; 51.3.2). En Persia, Antonio asedia y conquista Phraaspa (Plut., Ant. 38.140.9), y sufre algunos contratiempos en Armenia (Plut., Ant. 41.1-51.1); nueva victorias de Antonio (Plin., $H N$ 33.82-83). En África, el legado Statilius Taurus asegura el control de las provincias, que pasan al control de Octavio (Suet., Aug. 47.1; Dión, 49.14.6). Este, en Roma a su vuelta de Sicilia, recibe muchos honores, que incluyen la tribunicia potestas ( $R G$ 10; Vell., 2.81.3; App., $B C$ 5.130-132; Cass. Dio 49.15.1-6), recibe una ovatio por sus éxitos en Sicilia (Fast. Triumph, p. 109; RG 4; Suet., Aug. 22.1; Cass. Dio, 49.15.1), y premia a Agripa con una corona navalis (Liv., Per.129; Vell., 2.81.3; Sen., Benef. 3.32.4; Plin., NH 6.7-8; Suet., Aug. 25.3; App., BC 5.130; Cass. Dio, 49.14.3-4), etc. 
tradición, debe ser entregado para esta celebración. Una parte de ese oro lo gastó en el triunfo y la mayor parte, en la Regia").

\section{Año 34. C. Norbanus C. f. Flaccus procos. ex Hispania IIII id/us Ocltobr}

No tenemos noticias de este personaje antes de la muerte de César. Quizás fue pretor en el año 43. Le vemos en el campo de batalla de Filipos, Macedonia, bajo las órdenes de Antonio y Octavio, en su guerra contra los cesaricidas Bruto y Casio, en el año 42. Flaccus, junto a Decidius Saxa, frustraron las maniobras de Casio y Bruto (App., $B C$ 4.87.102, 103, 104, 106, 107 y 130; Plut., Brut. 38, Cass. Dio, 47.35-36), marchando luego a Amphipolis, donde Antonio encargó a Flaco que reuniera a todos los prisioneros supervivientes del ejército de Bruto y Casio. Posiblemente estas actuaciones contribuyeron a que se le otorgara a Flaco el consulado del 38, tras el cual-lo mismo que ocurrió con su predecesor Cn. Domitius Calvinus - fue enviado como procónsul a Hispania. En el trascurso del cargo, 37-34, debió tener algunas victorias contra pueblos indígenas indeterminados, celebrándolas el 12 de octubre del 36, como se indica en los Fasti Triumphales, p. 86 ss y 569, Degrassi; Fast. Barb. pp. 342-343; $\left.P I R^{2} 415, \mathrm{n}^{\mathrm{o}} 135\right)$. Se le atribuye la fundación de Norba Caesarina en los años 36-35 a.C., donde instaló a veteranos de sus campañas, posiblemente contra los lusitanos (si podemos deducir eso de la ubicación de la colonia). Como ocurrió poco antes con Calvino, parece que el consulado, primero, y el proconsulado de Hispania, después, son puestos o destinos políticos que muy bien pueden entenderse como recompensas por su participación y fidelidad en Filipos. Hispania no era en estos años un territorio conflictivo; más bien "pacífico" como muestran sus proconsulados trianuales, y la posibilidad y facilidad para obtener estos triunfos en Hispania, sin grandes esfuerzos y sin gran desgaste para los ejércitos de Roma aquí estacionados. Indicativo de esa falta de transcendencia político-bélica es el hecho de que no sepamos siquiera contra qué pueblos luchó Norbano para obtener una distinción tan prestigiosa como el triumphus.

\section{Año 33. L. Marcius Philippus ex Hispania V k. Mai. triumphavit palmam dedit. - Ap. Claudius Pulcer ex Hispania k. Iun. triumphavit palmam}

L. Marcius Philippus fue cónsul sufecto del 38. Cicerón (Phil. 3.25) le incluye entre los nueve pretores que rechazaron el reparto de provincias efectuado por M. Antonio en la sesión del Senado del 28 de noviembre del año 44 y que son citados por Cicerón en la Tercera Filípica (\$25-26). Cinco de ellos figuraron luego en las listas de proscritos por los triunviros del 43; pero otros cuatro, no; entre ellos L. Marcio Filipo, a quien el arpinate alaba su estirpe familiar (vir patre, avo maioribusque suis dignissimus). Fue enviado a Hispania como procónsul, a finales del 35 o en las primeras semanas del 34. Al año siguiente recibió los honores del triumphus, palmam, por desconocidas victorias o campañas contra pueblos hispanos (Fast. Barb. ad 33, Degrassi p. 342 ss y 569). 
Le sucede al mando de las operaciones en Hispania Ap. Claudius Pulcher, que había sido cónsul en 38. En el verano del 36 participó como comandante de la flota de guerra junto a Octavio, formando parte de su retaguardia en la formación de combate que parte de Puteoli hacia Sicilia, para combatir contra la armada de Plinio, comandante pompeyano, cerca de Lilybeo. Una tormenta espantosa arrojo los barcos contra las rocas, entre ellos la flota mandada por Pulcher (Vell., 2.79.4; App., BC 5.98-104; Cass. Dio, 49.1.1-6; Oros., 6.18.25). Este terrible contratiempo quedó resarcido con la victoria naval de Octavio en Nauloco (Vell., 2.79.5; Suet., Aug. 16.2; Flor., 2.18.7; App., BC 5.118-121; Cass. Dio, 49.8.1-11.1). Pulcher, por tanto, no destacó especialmente como militar, pero fue enviado a Hispania, con el rango de procónsul a inicios del año 33 (PIR $\left.2,237, n^{\circ} 982\right)$; en las primeras semanas o meses de ese año hace méritos suficientes para que se le reconozca un triumphus, de las mismas características que su predecesor, que reciben en fechas próximas, los días de calendas de mayo y junio del 33 (Fast. Barb., Degrassi p. 342ss y 570; en CIL X, 1423, 1424; ILS 890, se le califica de imperator).

Dos triunfos en tan corto espacio de tiempo (obtenidos por sometimientos de pueblos entre el verano del 34 y la primavera del 33) indican en una campaña "continuada", que denotaría cierta resistencia de los pueblos sometidos, pueblos que, de nuevo, quedan en el anonimato de las fuentes. Quizás se trate de vacceos, astures o cántabros, o varios de ellos a la vez, situados al norte del Duero. Con todo, no deja de ser sospechoso que dos militares no bregados obtengan triunfos tan rápidos y fáciles. ${ }^{6}$

A estos dos triunfos ex Hispania habría que sumar el de L. Cornificius, por sus triunfos ex Africa, cuya ceremonia se realizó en diciembre de ese mismo año 33. Brougthon (MRR II, p. 419, haciéndose eco de la opinión de Degrassi, Fasti, p. 570, indica: "perhaps rightly dates the triumphs of Claudius and Cornificius in 33, in spite of the very short interval after that of Marcius Philippus, since otherwise Cornificius

6 Los pueblos indígenas con los que entraron en lucha los romanos en el periodo estudiado (36-26/25 a.C.) son principalmente los del noroeste, a partir del año 29. Pero los triunfos de los generales triumphatores según los Fasti, de los años 36, 34 y 33 sometieron a algunas tribus de la Hispania Citerior. Así, en el 36, Cn. Domitius M. f. M. n. Calvinus procos., obtuvo los honores por su lucha contra los cerretanos, pueblo situado al sur de los Pirineos, ocupando el valle del río Segre. Sobre esta guerra, AmELA VAlverde 2009, 106-118. En el 34, C. Norbanus C.f. Flaccus procos., continuó la lucha. Al año siguiente, L. Marcius Philipus, recibió una palma del triunfo por someter a los vettones, entre los quedan restos onomásticos (cf. SaLINAS 1986, 189); y $A p$. Claudius Pulcer con pueblos (no especificados por las fuentes) de la meseta castellana, en la margen derecha del Duero. Parece que algunos de estos generales dejaron alguna clientela significativa, o al menos rastros de su onomástica. Badian 1984, 317, considera que los Marcii hispanos derivan del citado Marcius Philippus. Para el tratamiento de los pueblos del noroeste en conflicto, remito a las referencias bibliográficas dadas en el apartado I. Sobre la carrera de Domitius Calvinus: SwEENEY 1978, y sobre sus acuñaciones hispanas, GratAcós FreiXas 2002. Sobre la fundación de Norba Caesarina por C. Norbanus Flacus, ver Amela ValVerde 2009, 127 y nn. 647-648, con una veintena de referencias bibliográficas más. El último de los procónsules que celebró un triumphus ex Hispania, el año 26, Sex. Appuleius, fue posiblemente representado en el Ara Pacis, en opinión de Pollini 1986, 453-460 (espec. 457), con el argumento que dan los puestos religiosos de este senador, conocidos por una inscripción de Cartago, publicada hace más de un siglo por CAGNAT 1906, 470-78 $=C I L$ VIII, $24583=I L S$ 8963, un elogium que le menciona como flamen Iulialis, questor y praetor urbanus. Es el mismo personaje que, como procónsul fue enviado a Hispania, recibiendo un triumphus a su regreso, y años después fue enviado como procónsul de Asia en 23-22 (CAGNAT 1906, 477-477 y PIR 1², 1933, 186-87, $n^{\circ} 961$ (Groag). 
would have celebrated his during the war with Antony. This is the latest date possible and the one favored by Mommsen (CIL I ${ }^{2} .1$, p. 77$)$ ".

Existen varios años de lapso, entre el 33 y el 29, en los que Hispania no parece haber suscitado rebeliones o problemas políticos importantes, al menos no para Roma.

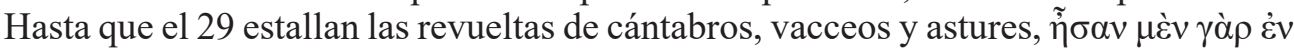

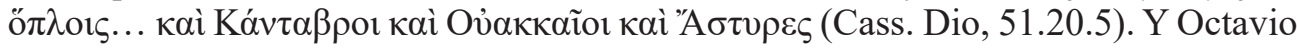
envía a un hombre experimentado en la guerra, con el que había compartido muchas jornadas de lucha, y estuvo a su lado en Actium ${ }^{7}$. Taurus, que había sido triumphator ex Africa como procónsul en el 34 (Triumph. Degrassi, p. 86 ss y 569; Vell., 2.127.5), no logró este premio por su intervención en el NO hispano, por lo que frecuentemente se ha subestimado su actuación. Creo que el "no triunfo" se explica por el hecho de que su intervención del año 29 fue más diplomática que militar, y por tanto su "expediente" de victoria no pudo ser considerado merecedor de un triunfo conforme a las reglas del derecho triunfal. Pero de hecho acabó con las luchas inter-territoriales entre cántabros, astures y vacceos. Éstos últimos, con la intervención de Tauro (Cass. Dio, 51.20.5), quedaron sometidos a Roma, y su territorio sería el trampolín, la base de operaciones, desde donde los romanos emprenderían el sometimiento de los cántabros y astures, enemigos de los vacceos y ahora de los romanos, que buscaban, o acaso tenían ya, una excusa perfecta para aniquilarlos: las incursiones en territorio administrado (antes o recientemente) por los romanos. ${ }^{8}$

\section{Año 28. [C. C]alv/is]ius [S/abinus ex Hispania VII k. Iun. triumphavit palmam dedit}

Es otro "hombre de César". Ocupó para él Etolia en el 48 (Caes., BC 3.34-35, y 56; App., $B C$ 2.60); pretor en el 46, gobernador de Africa Vetus en 45; regresó a Roma

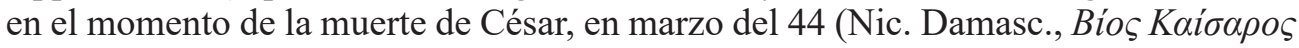

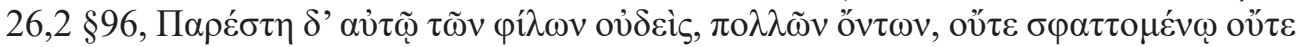

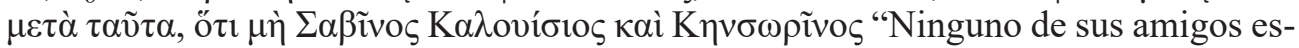
tuvo a su lado en los últimos momentos, ni cuando fue asesinado ni después, excepto Sabino Calvisio y Censorino"). Cónsul en el 39. Intervino en el bando de Octavio en

7 Había combatido junto a Octavio como procónsul, en Sicilia en el 36 a.C. (Oros., VI 18.32), en el contexto de las guerras civiles contra Antonio. Tras varios éxitos militares más, es enviado para pacificar las provincias norteafricanas, Africa Vetus y Africa Nova (App., BC 5.129; Cass. Dio, 49.14.6), donde se enfrentó con éxito a las tribus del desierto, obteniendo por ello un triunfo ex Africa, que celebró en Roma el 30 de junio de 34 a.C. (Cass. Dio, XXXXIX 14.6); en el verano del 34 luchó por la causa de Octavio en el Ilírico, tomando la plaza de Ninia (Liv., Per. 131.2; 132.1; Strab., VII 5.5; Cass. Dio, XXXXIX 38.4; Oros., VI 19.3); el mismo verano toma Setovia (Liv., Per. 131.2; 132.1; Suet., Aug. 20; Ap., Illyr. 27; Cass. Dio, XXXXIX, 38.4; Oros., VI 19.3); en el año 31, en los prolegómenos a Actium, luchó y venció a las tropas de Deiotaro Filadelfo de Paflagonia, un rey vasallo de Roma que se sumó a la causa de Antonio (Liv., Per. 132.3; Cass. Dio, L 13.5), y venció a las tropas antonianas en Prevedsa, Grecia (Liv., Per. 132.2; Cass. Dio, L 3.5; L 14.3; Oros., VI 19.7); y también luchó en Actium en septiembre del 31 junto a Octavio. Era, pues, un indiscutible "hombre de Octavio", al que siempre había servido con sus tropas, en Sicilia, África, Ilírico o Acaya, antes de ser enviado a la Hispania Citerior como procónsul.

8 Tauro, pues, cumplió con su misión, recibió el título de imperator tres veces, y en el 26, como cima de su carrera, alcanzó el consulado. 
la guerra de los triunviros. En el 37, cuando Menodoro defecta con seis o siete barcos de guerra para pasarse al bando de Sexto Pompeyo, se hace a Calvisio responsable de esa flota (el texto $C I L \mathrm{I}^{2} .2,1860=I L S 2468$, le cita como praefectus), aunque fue enseguida reemplazado por Agripa (App., $B C$ 5.96, cf. 100; Dio, 48.54.7; Oros., 6.18.25; Zonar., 10.24). Es posible que en el 35 se le asignase la misión de mantener el orden público en Italia (Brougthon, MRR II, p. 407). Su triumphus fue celebrado el 26 de mayo del 28 (CIL I $\mathrm{I}^{2} .1$, p. 50)

La intervención Sabinus en Hispania el año 28 fue lo bastante consistente como para mantener sin conflictos la Península Ibérica (obviada por las fuentes que relatan los episodios bélicos del NO) casi dos años, permitiendo a Roma cambiar el foco de sus intervenciones, los años 28 y el 27 , en otros conflictos, pues se documentan cuatro triunfos para generales victoriosos extra fines Hispaniae, registrados en las Acta Triumphales. A saber, el 28: [C. Carr]inas ex [G]al[l]is prid. eid. Iul.] triumph. palmam dedit; y L. Autronius P. f. L. n. Paetus procos. ex Africa XVII k. Septemb[r.]; y para el año 27: M. Licinius M.f. M.n. Crassus procos. ex Thraecia et Geteis IV non. Iul.; y M. Valerius M.f. M.n. Mesalla Corvinus procos. ex Gallia VII k. Oct.

\section{Año 26 (Tr. Cap.): Sex. Appuleius Sex. f. Sex. n. procos. ex Hisp. VII k. Febr}

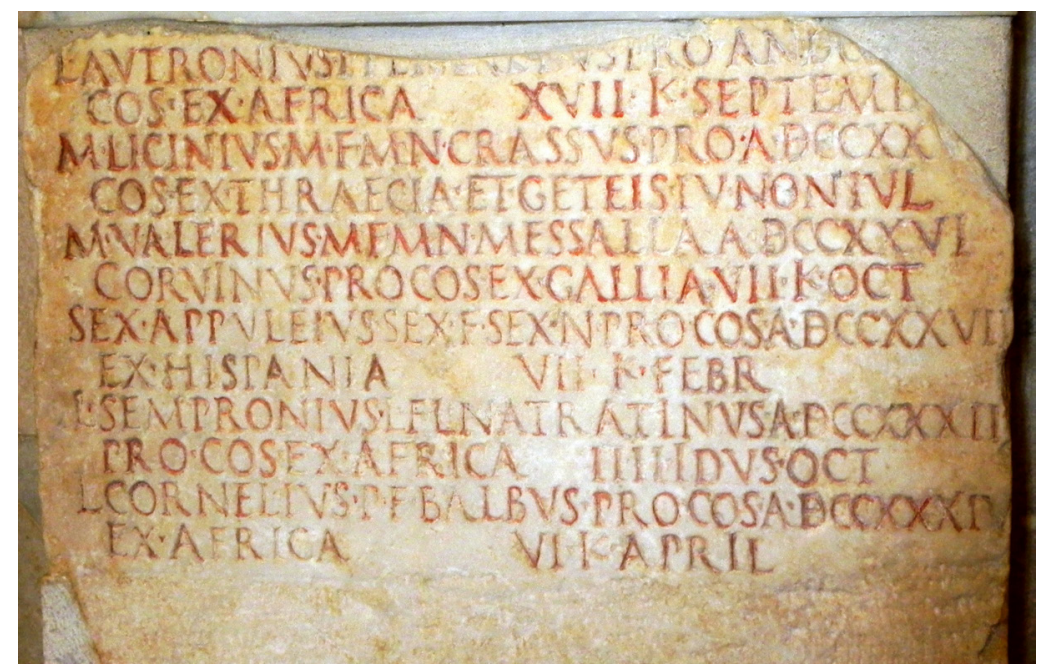

Fig. 1. Últimas líneas de los Fasti Capitolini, con el registro del triumphus ex Hispania de Sexto Apuleyo. Roma, Museos Capitolinos.

Appuleius fue cónsul en el 29 (año en el Octavio celebró su triple triumphus). Y fue Appuleius el último procónsul que celebró él un triumphus ex Hispania, el 26 de enero del año 26 (CIL I $\mathrm{I}^{2} .1$, p. 77). Este hombre, que sería enviado en 23-22 como procos. Asiae, estaría en la procesión de senadores del Ara Pacis, por razón de su amistad personal con Augusto y por sus cargos previos, flamen Iulialis, questor y praetor 
urbanus, según un elogium de Carthago (CIL VIII, $24583=I L S$ 8963), reexaminado por Pollini $(1986,457)$, y también por el honor de su triunfo contra los hispanos del cantábrico, poco antes de que el propio Augusto llegara a este escenario bélico. Su triunfo del año 26 queda registrado en los Fasti Capitolini (ver aquí la imagen) en la tabula final, que indica los nombres de últimos triumphatores republicanos de la Historia de Roma, donde se aprecia perfectamente la inscriptio (en las líneas 7-8 de este fragmento): SEX. APPULEIUS SEX. F. SEX. N. PROCOS. / EX HISP. VII K. FEBR.

\section{Año 26 y 25. [Imp. Caesar in] Hispania fuit (Fasti Latini).}

En efecto, el año 25 los cántabros y astures "reanudaron las hostilidades", кaì oi

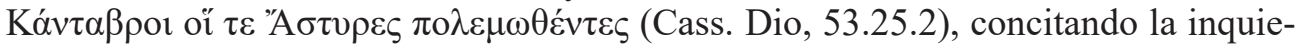
tud hasta el punto de tener que cambiar sus planes de ir a guerrear Britannia, o machar contra los salassos al pie de los Alpes (Cass. Dio, ibid.). Contra éstos últimos decide mandar a un ejército al mando de Terencio Varrón, con resultado exitoso (Cass. Dio, 53.25.3-5), decidiendo el propio emperador ponerse al frente del ejército que iba a combatir a los rebeldes hispanos:

En cambio, fue el propio Augusto quien dirigió la guerra contra astures y cántabros

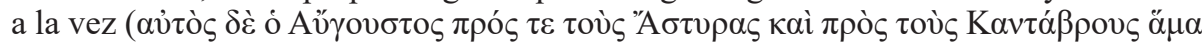

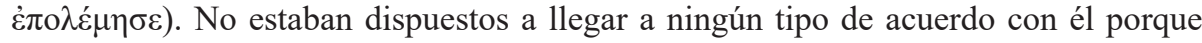
estaban llenos de ánimo confiados en sus fuertes, pero tampoco entablaban batalla campal para no ser derrotados, tanto por su inferioridad numérica como porque la

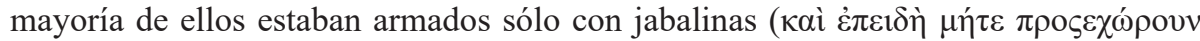

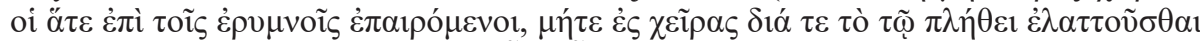

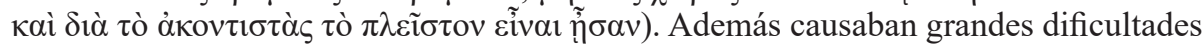
a los ejércitos cuando estos intentaban algún movimiento, puesto que ocupaban con antelación las posiciones dominantes y se emboscaban en las hondonadas y en las es-

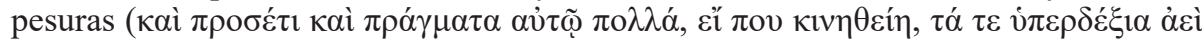

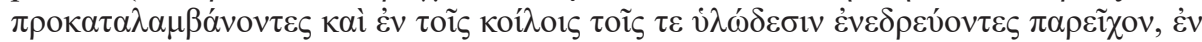

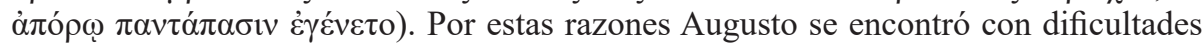
por todas partes. Cayó enfermo a causa del cansancio y de los desvelos, se retiró a Ta-

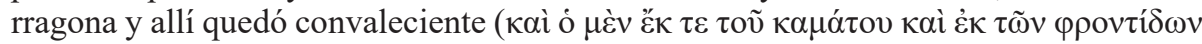

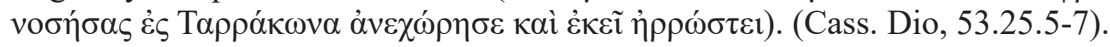

Los Fasti Latini mencionan el hecho sumariamente: [Imp. Caesar vale]tudin(e) impeditus fuit. Tarragona no acogió a un Augusto triunfante tras algo más de un año de campaña, sino a un Augusto cansado y enfermo que tuvo que ser trasladado en litera hasta la capital, con constantes cuidados médicos (Suet., Aug. 81); allí no esperó el tiempo propicio para la navegación, sino que decidió poner rumbo a Roma; y así lo hizo en enero del 24. Con su presencia en Roma acallaba los rumores acerca de su enfermedad o incluso acerca de su muerte (Horat., Od. III 14), iniciando de esta forma tan pesarosa su décimo consulado. Su mala salud no cesó, entrando en grave crisis el 23. 


\section{Continúa la guerra; años 25-19 a.C.}

Tras la retirada de Augusto del escenario bélico, la guerra no cesó sino que, al contrario, se reactivó, pensando los bárbaros que su victoria sería más fácil. Muy pronto el princeps se dio cuenta de que necesitaba la ayuda de un buen militar, y lo halló en Gayo Antistio Veto, hijo del Antistio que fue pretor en la Ulterior en el año 68, siendo César su quaestor. Antistio Veto había luchado en los ejércitos de César en el otoño del 45 o primavera del 44 en Apamea, en el contexto de las luchas de cesarianos contra pompeyanos (Liv., Per. 114.1; 121.1; Vel. Pat., II 69.2; Strab., XVI 2, 10), y más cercanamente, en el 33, había luchado contra los salassos en los Alpes (Ap., Illyr. 17). Era legatus Augusti propraetore en la Tarraconense desde el 27 al 24 a.C. ${ }^{9}$ Cass. Dio (53.25.8) nos habla de su intervención en el NO hispano: Гáı

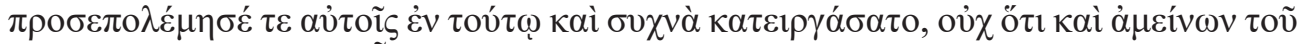

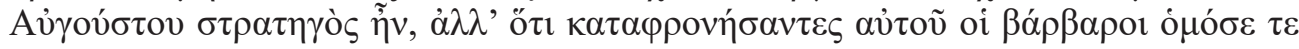

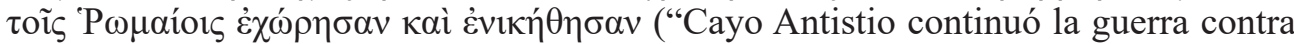
aquellos pueblos durante aquel tiempo y alcanzó notables resultados, no porque fuera mejor general que Augusto sino porque los bárbaros, despreciándolo, avanzaron hacia el encuentro con los romanos y fueron derrotados. Y así Antistio consiguió tomar algunas plazas". Antistio es relavado por Lucio Aelio Lamia,${ }^{10}$ el nuevo legado de la Citerior Tarraconense el año 24, asumiendo la dirección de la guerra (Cass. Dio, 53.29.1-2); con intervenciones rápidas y exitosas (Liv., Per. 135, 1; Cass. Dio, 53.29.1-2) que lograron ese "año de paz" al que se refiere el poeta Casiodoro en su Crónica del año 730 ab Urbe condita (= 24 a.C.): Astures et Cantabri per Lucium Lamiam pedomiti ("los cántabros y astures fueron sometidos por Lucio Lamia"). La tregua se rompió el año 22, y el nuevo legado de la Citerior, Gayo Furnio ${ }^{11}$ retomó puso a los soldados en armas -a los de las legiones I Augusta, II Augusta, IV Macedonica y IX Macedonica, así como a un número indeterminado pero significativo de tropas auxiliares-, desencadenó una campaña contra los cántabros en la que éstos fueron derrotados en lugar no identificado, que quizás sea el Mons Medullius (Liv., Per. 135, Cass. Dio, 54.5.1; Flor., 2.33.50; Oros., VI 21.6). Estas victorias fueron

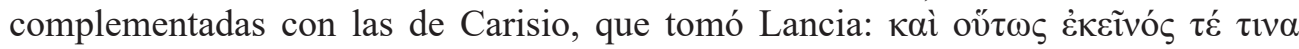

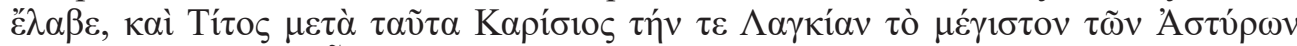

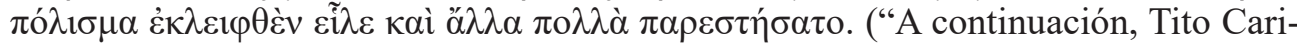
sio, después de que la abandonaran, capturó Lancia, la mayor ciudadela fortificada de los astures. Y consiguió someter otros muchos lugares" (Cass. Dio, 53.25.8). Los métodos expeditivos de P. Carisio en territorio astur-donde las legiones VI y X, bajo su mando, mantenían el orden-, ${ }^{12}$ y la acción de Gayo Furnio sobre los cántabros el año $22,{ }^{13}$ produjo un gran número de esclavos, que fueron enviados a la Galia o a las cercanas minas del Noroeste. El mazazo supuso una nueva tregua, pero no el someti-

\footnotetext{
9 AlfÖLdy 1969, 3-5.

$10 P I R^{2}$, A 199; AlfÖldy 1969, 5-6.

11 AlfÖldy 1969, 6.

12 Alföldy 1969, 131-132.

13 AlFöldy 1969: 6-7.
} 
miento completo. Posiblemente en los trabajos forzados de la minas se concentraron los prisioneros más fuertes y más audaces, hasta el punto de iniciar levantamientos, en el 20 y en el 19 (Cass. Dio, 54.11.2), y quien debía acabar con este problema era el nuevo legado P. Silius Nerva,${ }^{14}$ un "hombre blando", sin experiencia en el campo de batalla, que no era, obviamente, la persona adecuada. El problema no eran tanto estas insumisiones de los aguerridos bárbaros del noroeste, ya libres ya prisioneros, sino las noticias que llegaban a Roma en el sentido de que Augusto parecía incapaz de imponer el yugo de Roma a estos pueblos alticos, como se oía en labios de los poetas cortesanos (Horat., Od. 2.6.1).

Si he recordado sumariamente estos episodios bélicos del finales del 25 al 19 es para indicar que, de manos de uno $u$ otro legado, hubo acontecimientos bélicos de suficiente entidad como para haber celebrado triunfos. Pero no ocurrió así. La razón me parece clara: si el propio Augusto, con su presencia in situ, no pudo "arrancar" un triunfo en el noroeste hispano, tampoco podrían hacerlo los generales que le sucedieron en el escenario bélico. Del mismo modo que los generales que actuaron aquí antes del 25 tuvieron muy fácil la consecución de sus triunfos, los que estuvieron luchando en Hispania después del 26, no lo iban a obtener, aunque hiciesen más méritos. El punto de inflexión, insisto, es el año y pico de campaña de Augusto en Hispania y su "no triunfo", que supuso un cambio drástico en la política augustea respecto a la concesión de los triunfos. No carece de interés el hecho de que Augusto -que escribió una Autobiografia de sus años de juventud y madurez, obra de la quedan breves fragmentos-, acabara sus memorias precisamente con su visita al frente cántabro por motivo de la guerra (Suet., Aug. 85: Cantabrico tenus bello nec ultra exposuit), aunque fue publicada unos años después, coincidiendo con la restitución de los signa militaria que los partos habían arrebatado a los romanos. Augusto consideraba, pues, que el bellum Cantabricum significaba para él el cierre de un ciclo vital con entidad propia: el final de su periodo de formación como político, como militar que pisa los teatros de operaciones del dios Marte, no sin sufrimientos ni peligros, en lejanas regiones, en durísimos parajes. Por pura coincidencia ese hito en la vida del princeps lo es también para las gentes Cantabrorum, que con él cerraron el ciclo de su "feliz independencia bárbara" para quedar sometidos a las armas, a los dioses, y a las leyes de Roma. Y de hecho así es como resume Pompeyo Trogo (en el epítome de Justino, 44.5. 8) el programa político de Augusto en la región astur-cántabra: populumque barbarum ac ferum ad cultioris vitae usum traductum. Y por tal razón se cerraron de nuevo las puertas del templo de Jano (Cass. Dio, 53.26.5; Oros., 6.21.11).

El verdadero cambio ideológico respecto a la política triunfal se produjo realmente en el año 29, como enseguida veremos, y que tiene punto final, para Hispania, el 25, y en el conjunto del imperio, el año 19. Entre el 25 y el 19 solamente se celebrarían dos triunfos en Roma: el de L. Sempronius Atratinus el año 21, y el de L. Cornelius Balbus el año 19, en ambos casos por sus victorias en África. ${ }^{15}$

14 ALFÖLDY $1969,7$.

15 Atratinus: L. Sempronius L. f. L. n. Atratinus a. DCCXXXII pro co(n)s(sule) ex Africa IIII idus Oct. (Fast. Triumph. Capit. ad ann. $21=$ Inscr. Ital. XIII, 1, p. 86 ss.; Tab. Triumph. Barb. ad ann. $21=$ Inscr. Ital. 


\section{Octavio y sus triunfos del año 29. Un giro conceptual ${ }^{16}$}

Octavio celebró en Roma, los días 13-15 de agosto del 29 los tres triunfos recientes, por el sometimiento de Dalmacia, Egipto y la victoria naval de Actio ( $R G$ 4; Suet., Aug. 22; Virg., Aen. 8.714), un hito en su trayectoria política futura y en el devenir de la historia de Roma. El 2 de septiembre del 31, la flota de Octavio, mandada por Agripa, reunió 400 naves ligeras. Solo en cuatro horas pusieron en fuga a los 230 pesados barcos de Marco Antonio. La victoria fue, como es bien sabido, un episodio crucial en la vida de Octavio, y clave en el devenir de la propia historia de Roma. El combate naval tuvo continuidad durante más de un año, bien por tierra bien por mar, con múltiple escaramuzas y encuentros militares de resultado incierto.

Concentrar la celebración de varios triunfos era una cuestión de orden práctico, pero posiblemente también estaba en la mente de Octavio emular la celebración conjunta, por parte de Julio César, en junio del año 46, de su cuádruple victoria ex Gallia, ex Aegypto, ex Ponto, ex Africa de rege Iuba (Bell.Hisp. 1,1; Liv., Per. 115; Plut., Caes. 55.2; Suet., Caes. 37.1; App., BC. II 101; Cass. Dio, XLIII 19-22); o incluso es posible que hubiera, yendo aún más lejos en su intención política y más atrás en el tiempo, un intento de emular o ponerse a la altura de Pompeyo Magno que en los días 28-29 de septiembre del 61 celebró ostentosamente tres triunfos por haber "liberado las costas marítimas de los piratas y devuelto la soberanía del mar al pueblo romano, con triunfos en Asia, Ponto, Armenia, Paflagonia, Capadocia, Cilicia, Siria, contra los escitas, judíos, albanos, iberos, cretenses, bastarnos y, además, sobre el rey Mitrídates

XIII, 1, p. 344 ss.). - Balbus: L. Cornelius P.f. Balbus pro co(n)s(sule) a ĐCCXXXIV ex Africa VI k. April. (Fast. Triumph. Capit. ad ann. 19 y 571; Strab. 3.5.3).

16 Sobre Octavio-Augusto se han escrito muchas biografías generales, de valor desigual, y de interés dispar para el asunto aquí tratado, el de los triunfos y los aspectos militares de Augusto. Recomiendo especialmente el estudio de Brigmann 2008. Otras biografías más recientes, como la que cito a modo de ejemplo, son insustanciales, como la de GALINSKY 2012. Una visión de conjunto sobre su largo reinado, con abundante y cualificado material gráfico, podemos verla en el catálogo de la reciente exposición AvGVSTVS habida en Roma desde septiembre de 2013 a febrero de 2014, obra que ha sido coordinada por LA RocCA, libro del que me han interesado especialmente tres estudios: el de PresicCE ibid., 118-129 (que presta especial atención al significado militar-diplomático de la representación de la coraza del Augusto de Prima Porta); el de Giroire ibid., 289-291 (con mención de la importancia que tenía para Augusto la conquista de los reductos territoriales extremos, como era el NO hispano), que se complementa con el trabajo de RoGer, "Ottaviano conquista il potere assoluto", ibid. 141-152. Además, interesan algunas obras monográficas y artículos sobre Augustus triumphator: sobre las dos importantísimas sesiones del Senado en Roma los días 13 y 16 de enero del año 27, LACEY 1974, que hay que complementar ahora con el estudio de FrEYBURGER-GALLAND 2009. Los fragmentos de Casio Dión citados aquí en español están tomado de la versión de CoRTÉs COPETE 2011. Sobre el proyecto iconográfico de Augusto en el Campo de Marte, a propósito de la devolución de los estandartes arrebatados a Craso y devueltos por Fraates, tras un acuerdo diplomático, remito al clásico estudio de ZANKER 1992, especialmente pp. 225-249, así como el de KLEINER 1988. Sobre las victorias militares y los triunfos de Augusto en especial: BARNes 1974; Hickson 1991, 125-138 (el propósito del artículo es mostrar "As Princeps, Caesar Augustus manipulated political ceremonial and exploited the visual media in such a way as to monopolize, for himself and his intended successor, the image of triumphator", ibid. p. 125); HJoRT LANGE 2009 (obra de la que interesan especialmente las pp. 95-120, sobre la Victoria de Actium y su significado político, y pp. 148-155, sobre el triple triunfo celebrado por Octavio en el año 29); TARPIN 2009, 129-142 (importan especialmente las páginas 136-141 sobre el "espíritu republicano" del triple triunfo celebrado en Roma por Augusto el año 29). Sobre el programa propagandístico político de Augusto y su aplicación en Hispania, RAMAge 1998. 
y Tigranes" (Plut., Pomp. 45.1). La celebración de la triple victoria de Octavio el año 29 , por tanto, se inscribe en la tradición tardorrepublicana del ceremonial triunfal múltiple, y además, lo concluye. El libro publicado por Tanja Itgenshorst es radical en este sentido. ${ }^{17}$ La celebración triunfal del 29 es el punto final del triunfo puramente republicano, el único que debe ser considerado como tal por su esencia y sus formas republicanas. En época imperial el triumphus tradicional habría perdido su esencia por "contaminación" del ritual imperial, según sostiene C. Barini, ${ }^{18}$ un ritual imperial-triunfal distinto que tiene punto de partida en el ceremonial de Tito por su victoria sobre los judíos el año 71, como sostiene E. Künz. ${ }^{19}$

Merece la pena que nos fijemos un poco en el triumphus del 29: mencionado brevemente por la períoca 135 de Livio, es narrada también con suma brevedad por Suetonio (Aug. 22.1), que en este punto plagia el fragmento de $R G$. La narración de Veleyo (II 89) aporta poco. El relato más detallado es el de Casio Dión, por tanto indirecto y un tanto alejado de los acontecimientos (51.19 y siguientes). En el largo relato de Dión no se observan grandes discrepancias con el triumphus republicano. Se respeta en general el ceremonial republicano, salvo en algunas cosas "nuevas", considerada así por el propio Dión: la realización de una supplicatio, que realiza el cónsul sufecto de ese año, Potitus (51.21.2), y cierta arbitrariedad en la colocación de los senadores que forman parte de de la procesión. Se nos escapan los detalles de esa disposición de los senadores, pero sí sabemos que Octavio los tenía en gran estima pues fueron parte fundamental de su proyecto político. De su apoyo efectivo se jacta el propio Augusto cuando recuerda las guerras en las provincias, tras Actio, asegurando que contó con más de 700 senadores: ... quo vici ad Actium ducem depoposcit. Iuraverunt in eadem ver[ba provi]nciae Galliae, Hispaniae, Africa, Sicilia, Sardinia. Qui sub [signis meis tum] militaverint ( $R G 25)$.

De ese ceremonial del 29 quiero destacar cómo, antes del desfile, Octavio felicita a

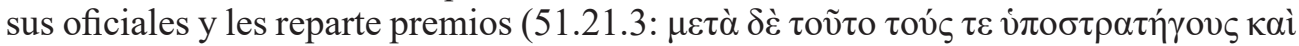

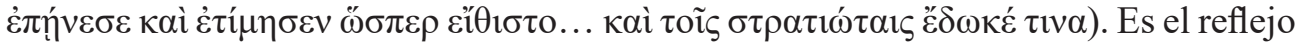
en el ámbito civil de una contio clásica que debía tener lugar en el campo de batalla, y que se reproduce aquí añadiéndole un plus de sacralidad. Dión destaca un hecho excepcional, único: la concesión por parte de Octavio a Agripa de un estandarte azul

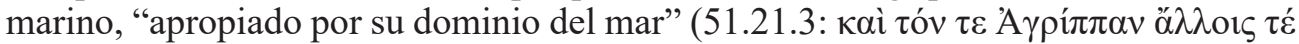

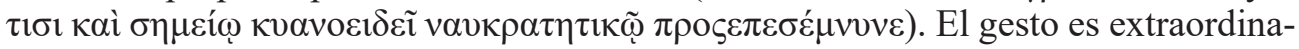
riamente simbólico e importante: en un momento tan solemne -inmediatamente precio al desfile de la pompa triumphalis - la concesión de este estandarte azul marino indica el poder (militar) de los mares, como si Augusto, como una especie de Neptuno, le confiriese ese poder a Agripa. No es una idea banal. Pues había precedentes, y muy cercanos, cuando Sexto Pompeyo, en el verano del año 42 resultó vencedor de un encuentro naval contra la flota de Octavio, mandadas por el legado Q. Salvidienus Rufus Salvius, que habían partido desde Rhegium (hoy Reggio di Calabria), siendo esta flota derrotada (App., BC IV 96; Cass. Dio, 47.12.2; 48.17.3). El impetuoso Pompeyo se

17 ITGENSHORST 2005.

18 BARINI 1952.

19 KÜNZ 1988. 
ufanó de su victoria con desmesura, hasta presentarse él mismo como el dios del mar, ea fuerit elatus insania, ut Neptuni se filium iactaret, vistiéndose un manto del color del mar profundo, en un acto con cierto gusto teatral, tal como lo relata Apiano $B C$ V 100: "Sexto Pompeyo... realizó un sacrificio al Mar y a Neptuno, y aceptó ser llamado hijo de éstos, convencido de que los enemigos habían sido derrotados por dos veces, de este modo, en el verano, con la ayuda de la divinidad. Y se cuenta que él, enorgullecido por estos hechos, también cambió la habitual clámide de los generales romanos de rojo púrpura al azul oscuro, queriendo significarse así como el hijo

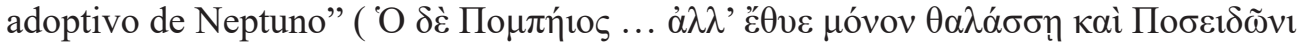

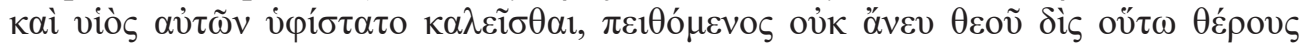

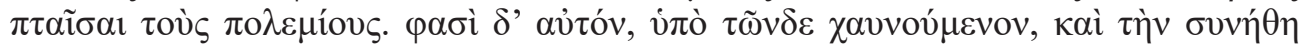

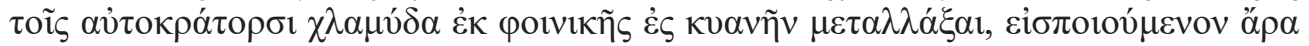

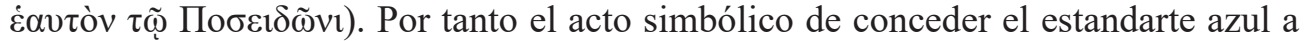
Agripa no fue improvisado, sino que vino a ser un acto reivindicativo y "restitutivo", y tenía, entre otras finalidades, presentar a Agripa como el verdadero Neptuno, señor del mar, vencedor por tanto, también, de Sexto Pompeyo, el gran enemigo de la nueva res publica cuya forja casi definitiva se estaba urdiendo ese año $29 .{ }^{20}$

Desde el punto de vista militar, Octavio emula y alcanza, a nivel de auto-propaganda pública, los logros militares de tan egregios predecesores -¡Pompeyo y César!por tierra y mar: bella terra et mari civilia externaque toto in orbe terrarum saepe gessi $(R G$ 3.1). El proyecto de "cerrar el dominio del orbe" era entonces, desde el año 29 , algo urgente; y en la lista de los territorios pendientes de anexión definitiva estaba el noroeste hispano. Su conquista fue tomada en serio, aunque con intensidad e interés intermitente, como reflejan los propios Fasti con la mención de triunfos ex Hispania. La conquista del NO hispano se convirtió en un problema "en vías del solución" desde el año 29 al 25; un "problema abandonado al olvido" o "dejado pudrirse" del 25 al 19, fecha última en que, una vez más, Agripa "hizo el trabajo" ad maiorem gloriam Augusti en su calidad de Imperator.

Octavio nunca ocultará los méritos de Agripa en las victorias que fueron decisivas, pero tampoco lo publicita o lo explicita en los Fasti Triumphales. La deuda "militar" que Octavio tenía contraída con Agripa era inmensa, y ambos lo sabían. La presencia de Augusto en el NO hispano los 26 y 25 no supuso en absoluto el sometimiento definitivo de estos pueblos, como bien sabemos. Aunque si utilizamos como fuente únicamente los Fasti Triumphales da la impresión de que, efectivamente, Augusto sometió definitivamente a estos pueblos, pues, ocurre que las luchas posteriores (entre el 25, año del regreso de Augusto a Roma, y el mazazo atestado definitivamente por Marco Agripa el año 19 a.C. a los cántabros), no están registradas con ningún triumphus en los Fasti, sin razón aparente. Al menos debería figurar la intervención -este vez sí concluyente de Agripa el año 19-, pues el registro oficial -y la inscripción monumental que lo reproducía- llega precisamente al citado año 19 , momento en

20 Casualidades de la vida, ese año 29, “del triunfo de la paz”, Octavio en su quinto consulado tuvo como colega a Sexto Apuleyo, un hombre que muy pronto habría de ser enviado al norte de Hispania a combatir con varias legiones a esos irreductibles cántabros de los que ahora llegaban noticias a Roma de sus primeras revueltas. 
que cesa este registro y acaba la inscripción monumental. Esa fecha post quem con la que se cierra el relato de triumphatores en los Fasti Capitolini explica la ausencia del nombre de M. Agripa en tal elenco honorífico.

El año 19, conclusivo de las guerras en Hispania, coincide con la fecha de la restitución de los estandartes arrebatados por los partos a Craso, a iniciativa de Fraates. Augusto - emulando al fundador Rómulo- hizo construir un templo a Mars Ultor -a imitación del Júpiter Feretrius - en el Capitolio para colocar allí ese tesoro recuperado (Cass. Dio, 54.8.3). El mismo año Augusto hace el voto por una ovatio recibida y ordena la construcción de un arco triunfal en el Foro, coronado con el grupo escultórico de una cuadriga en marcha. Hay quien duda que este arco se llegara a construir, y en todo caso, ha desaparecido; lo vemos representado en algunas monedas. El acontecimiento lo sintetiza Dión: “... ordenó que se decretasen sacrificios en honor de aquellos sucesos, así como que se ofreciese un templo a Ares Vengador en el Capitolio, según el ejemplo del templo de Zeus Feretrio, para dedicar en él los estandartes. Y él mismo ejecutó aquellas decisiones. Además, entró en la ciudad a caballos

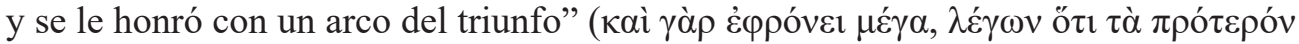

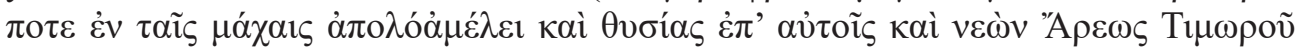

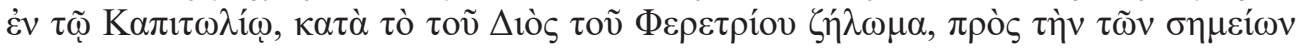

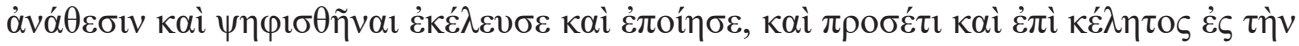

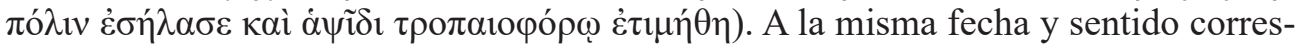
pondería, la estatua de Augusto hallada en Primaporta, según Zanker, que ha estudiado todo este programa iconográfico. ${ }^{21}$

Acto seguido, Augusto decide inscribir un triunfo para Rómulo, y manda que inscriba en piedra la lista del registro oficial de los triumphatores republicanos, ab ini$t_{i o}{ }^{22}$ hasta el año 19, cerrando así el círculo Romulus-Augustus. El primero de los tres triunfos celebrados por Octavio en el 29, es citado Rómulo como modelo y prístino fundador (triunfador) de Roma, primus conditor urbis (Fast. Triumph. Capt. ad ann. 753 = Inscr. Ital. XII.1, p. 64 ss y 534). Con ese acto quedaba clausurada constitucionalmente la costumbre de inscribir a los generales victoriosos en una lista oficial, de modo que pasaba al emperador, y a sus sucesores, el monopolio de la ceremonia triunfal. ${ }^{23}$

21 ZANKER 1992, 225-249.

22 Aunque las listas de triumphatores que se admitan con verosímil certeza empiezan en el año 339, ininterrumpidamente hasta el 19 a.C.., con excepción de ciertas lagunas no muy largas, combinando distintas inscriptiones fastorum para completar el elenco; todas ellas editadas por Degrassi en Inscr. Italiae XIII.1.

23 Hickson 1991, 128; Perea Yébenes 2002-2003, 155-156; Bastien 2007, 74. 


\section{Augustus victor y la declinatio Agrippae ${ }^{24}$}

Para cerrar definitivamente el problema hispano, Augusto cursa la orden a Marco Agripa, que estaba en la Galia. Viaja a Hispania, año 19, donde se reúne con el legado Publio Silio, y marchan al escenario de la guerra. Sólo un hombre experimentado como Agripa pudo enderezar la situación. En primer lugar, tuvo que poner orden en las legiones, que estaban desmoralizadas, y quizás amotinadas, por tantos años de lucha contra los cántabros.

Para la actuación de Agripa en Hispania, nos aferramos al relato de Dión (54.11 ss). Tras solucionar asuntos bélicos y diplomáticos en la Galia, Agripa llega a Hispa-

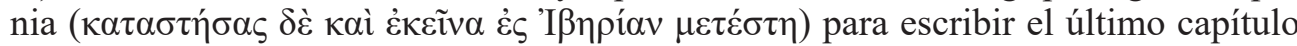
de las guerras cántabras:

... pues los cántabros que, derrotados en la guerra, habían sido vendidos, mataron a sus respectivos dueños $y$, tras volver a sus casas, levantaron en pie de guerra a otros muchos. Con su ayuda capturaron algunas plazas y tras fortificarlas atacaron las guarniciones romanas. Cuando Agripa condujo una expedición contra estos sublevados, se encontró con ciertos problemas entre sus propios soldados. No pocos de ellos eran ya mayores y estaban cansados de aquella guerra interminable. Además, temían a los cántabros, a los que consideraban difíciles de derrotar. Y por todas esas razones se negaron a obedecerle. Pero él consiguió que le obedecieran inmediatamente, con amonestaciones y consejos, pero también dándoles esperanzas. En los enfrentamientos contra los cántabros sufrieron muchos reveses. Estos no sólo demostraban un mejor conocimiento de las tácticas romanas, puesto que ya habían estado sometidos a Roma, sino que también demostraban que no tenían esperanza alguna de seguir vivos si eran capturados. Pero al final, tras perder a muchos soldados y privar de sus derechos a otros muchos por haber sido derrotados -y así, por ejemplo, entre otras medidas, prohibió que toda aquella legión llamada Augusta siguiera usando aquel títulos-, consiguió aniquilar a casi todos los enemigos que estaban en edad de luchar. A los demás les arrebató las armas y los hizo bajar a los llanos desde sus posiciones fortificadas. (Cass. Dio, 54.11.2-5)

Los severísimos castigos ejemplarizantes de Agripa a algunas de sus legiones (Cass. Dio, 54.11.3-5), particularmente, según parece, la I Augusta, son a todas luces excesivas para reprimir un pequeño motín o un superar un estado de desánimo. La decimatio de la legión Primera y la supresión de su título honorífico Augusta, se debió con toda probabilidad, como ya se ha apuntado, a la pérdida del aquila, hecho anterior a la llegada de Agripa. La diplomacia, si es que en algún momento existió en

24 La vida de Marco Agripa, amigo, familiar, general de Octavio-Augusto, artífice de su poder y consors del Imperio al final de su vida, merece una atención especial. Disponemos de dos obras fundamentales, dos biografías monumentales, que cubren nuestras expectativas para el presente trabajo y las de cualquier lector interesado en el personaje: REINHOLD 1933; RoDDAZ 1984 (sobre las guerras cántabras y el papel de Agripa, pp. 402-418); ver también Roddaz 1993, 111-126, con particularidades sobre la acción política de Agripa en Hispania. RodDAZ 1984, 185-187 habla de la cuestión del estandarte azul entregado por Octavio a Agripa, al que alude Casio Dión 51.21.3. Sobre la comparación de este acto simbólico con el precedente de Sexto Pompeyo, narrado por Apiano, BC V.100, remito a mi estudio reciente, Perea YéBenes 2013, 147-167. 
el bellum cantabricum, había caducado para dar paso a la parte más brutal y cruda de la guerra (Cass. Dio, 54.11.1-6; Vell., 2.90.1; Flor., 2.33.51), poniéndole fin. Las noticias que llegaban a Roma, verdaderas o manipuladas, hablaban del "loco heroísmo de los cántabros que cantaban victoria mientras eran crucificados" (Strab., III 4.18). Con toda seguridad, el estandarte de la legión Primera fue recuperado, y las insignias bárbaras fueron echadas en las carretas, en un largo viaje que tenía como punto final ser llevados a Roma: los signa recepta tendrían sede en el templo de Mars Ultor ( $R G$ 29), y los trofeos de los bárbaros cabe suponer que en el templo de Júpiter, junto a los spolia opima de las naciones extranjeras sometidas, según la costumbre. Y Agripa cruzó victorioso Hispania con sus tropas, mostrándose aquí como benefactor, allá como patrono de algunas colonias, quedándose en una Hispania pacificada hasta la primavera del año 18. Una imagen, un paseo, que con mucho gusto hubiera querido protagonizar el propio Augusto un quinquenio antes. ${ }^{25}$ Pero, al fin y al cabo, Augusto "ya había celebrado su triunfo" por anticipado -recuérdese que el 1 de septiembre del año 22 Augusto dedicó el templo de Iuppiter Tonans en el Capitolio en recuerdo y conmemoración de haber salido indemne en Cantabria de la caída de un rayo (Suet., Aug., 29)-, y su yerno Agripa también sería recompensado el imperium proconsulare y la potestas tribunicia. Lo importante es que Agripa, como vir militaris ejemplar, no hacía la guerra ni conquistaba para sí, sino para los romanos, y para el princeps.

Al menos oficialmente, en la tabula fastorum triumphatorum, el pacificador definitivo de Hispania es Augusto, en tanto general e imperator, privilegio que le debía corresponder realmente a Agripa. Existe, por tanto, una "disfunción" o "falsificación" de los registros oficiales, a propósito de Hispania, que sólo puede explicarse por las relaciones de Augusto y Agripa en tanto militares, parientes, amigos y hombres de Estado, y que se resume en con solo hecho: la generosa decisión de M. Agripa de renunciar a los honores que legalmente le correspondían, según la tradición del derecho triunfal romano, para cederle ese privilegio a Augusto.

Dión se ha ocupado de transmitirnos una imagen de Agripa como un hombre verdaderamente excepcional, estrecho colaborador de Augusto, de su política-exterior, como militar, e interna, como hombre de Estado o constructor de edificios-, un hombre caracterizado por su honestidad, sencillez y falta de soberbia. Tras acabar las obras de los Saepta, el año 26, en el Campo de Marte, "Agripa con estas acciones no sólo no se acarreó la envidia de nadie, sino que recibió grandes muestras de reconocimiento tanto de Augusto como de todos los demás. La razón estaba en que cuando prestaba su consejo a Augusto o colaboraba con él en los más generosos, gloriosos y provechosos de sus proyectos, Agripa no aspiraba ni a una mínima parte de la gloria que estos pudieran aportarle, y en que tampoco utilizaba los honores que recibía de Augusto ni para enmarcar su preponderancia ni en provecho propio, sino en beneficio del propio Augusto y del pueblo" (Cass. Dio, 53.23.4).

25 Lo que hizo Augusto unos años más tarde, en su tercer viaje a Hispania (el primero fue el año 45, siendo aún un jovencísimo Octavio; el segundo, el año 25, ya comentado), una vez conquistada totalmente, entre el 16 y el 13 a. C., según Syme, para la reorganización administrativa de las provincias (Cass. Dio, 54.4.23-25: Flor., 2.33.59; App., Iber. 101), fundando algunas colonias con licenciados de esta guerra y reforzando otras con aportes de aportes de veteranos de estas guerras. 
El párrafo dioneo indicado antes, que narraba la intervención de Agripa en el frente cántabro el año 19 concluía con la significativa frase de que el general romano había conseguido "la aniquilación de los enemigos y la entrega de las armas" ( $\tau$ oú $\tau \varepsilon \varepsilon \dot{\varepsilon} v$

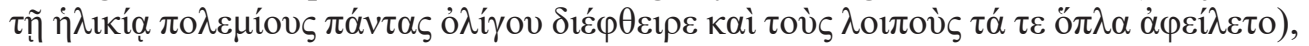
lo que, según el derecho triunfal republicano le hacía merecedor de un triunfo, que debía ser aprobado por el Senado tras el examen del preceptivo "informe de guerra" redactado por el general victorioso en el escenario de la carnicería. Sin embargo, indica Dión (54.11.6), Agripa "no envió ningún informe al Senado sobre sus actuaciones ni tampoco aceptó el triunfo, a pesar de que se le había decretado por mandato de Augusto. También en aquellas circunstancias se comportó con la moderación que

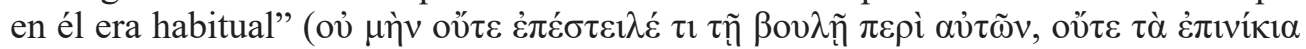

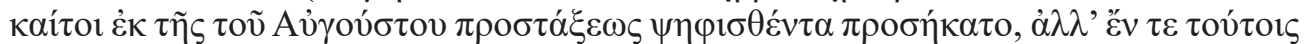

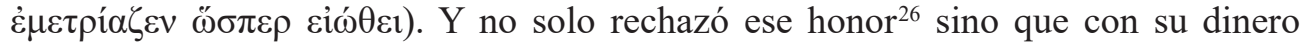
prolongó uno de los acueducto que llevaba agua a Roma, dándole el nombre de "augusto" (se trata de Aqua Virgo Augusta, inaugurado el 9 de julio del 19 a. C.) (Cass. Dio, 54.11.7). Y concluye acerca de la generosidad de Agripa y sus valores morales a propósito de la declinación del triumphus por su victoria en Hispania: "Así era aquel hombre. Mientras, otros trataban de conseguir el triunfo e incluso llegaban a desfilar, pero no porque hubiesen conseguido logros parecidos a los de Agripa sino porque, o bien habían capturado a algunos ladrones, o bien habían conseguido poner orden en ciudades que sufrían crisis internas. Augusto, al principio, otorgó estos honores a algunas otras personas con generosidad, así como honró a otras muchas con funerales públicos" (Cass. Dio, 54.12.1). El párrafo, unido a los anteriores, es interesantísimo. Es verdad que Agripa no quiso tramitar la solicitud de triunfo al senado el año 19, pero realmente era una cuestión espinosa, pues el propio Augusto ya había sido aclamado por sus "victorias" en Hispania el año $25,{ }^{27}$ y Agripa de ningún modo quería

26 Antes y después de esta fecha, un joven Agripa ya había declinado la celebración de triunfos a los que el propio Octavio le había invitado. Así ocurre en el 36 cuando Agripa vuelve a Roma, desde Galia, posiblemente de Aquitania, para acceder al consulado y tomar el mando de las operaciones contra Sex. Pompeyo, momento en que Agripa rechaza el honor del triunfo ex Gallia que le ofrece Octavio (Cass. Dio, 48.49.3-4). Tras Actium, como sabemos, "cambió" los honores del triumphus por recibir los ornamenta triumphalia; en el 14 vuelve a inhibirse respecto a su celebración de triunfo por su victoria contra los cimerios del Bósforo (Cass. Dio, 54.24.7)

27 Cabe recordar que el motivo de la erección del ara Pacis Augustae, como se indica en Res Gestae Divi Augusti 12.2, fue precisamente el regreso "a Roma, desde Hispania y Galia, una vez resueltos favorablemente los asuntos de esas provincias", cum ex Hispania Galliaque, rebus in iis provincis prospere gestis, Roman redi. Aquí vemos un desajuste temporal: pues sabemos que el regreso de Augusto fue el año 25, que el final de las guerras fue el 19 a.C. y que el ara Pacis fue consagrada el 13 a.C., siendo cónsules Ti. Nero y $P$. Quintilius. El estilo lapidario y seco del texto, que hace honor a la brevitas imperatoria-brevedad y economía de palabras en el estilo literario de Augusto- da lugar a equívocos, pero también da idea de lo absolutamente medida que está la redacción de Res Gestae. En estas líneas, de nuevo Augusto se arroga el mérito que no le corresponde sensu stricto, el de la "pacificación total", manu militari, de las tribus cántabras, y dice una verdad a medias cuando indica que el "Senado decretó la erección del ara en el Campo de Marte por mi feliz regreso" (aram Pacis Augustae senatus pro reditu meo consacrandam censuit ad campum Martium), cuando debería decir "la conmemoración de mi feliz regreso". Pero como el texto de las Res Gestae tiene un sentido memoralístico, y de balance personal, esos matices quedan hábilmente disimulados, pues, en efecto, como indica, Luca Canali $(1982,15)$, las Res Gestae son, literariamente, de un estilo aticista lapidario, "obviamente, ma sopratutto strumento di asseverazione e di sintesi, al cui interno le antonomie fattuali si presentano già 
arrebatar ese privilegio al emperador, acto que hubiera sido visto como un gesto de rivalidad, algo que no era concebible en la mente de ambos. Agripa pudo comprender, y aceptar, parece que de buen grado la decisión de Augusto de ser considerado el fundador de un Estado "que fuese el mejor de todos", ut optimi status, una ambiciosa empresa personal, como dejó literalmente escrito (Quam voluntatem, cum prae se identidem ferret, quodam etiam edicto his verbis testatus est: "Ita mihi salvam ac sospitem rem $p$. sistere in sua sede liceat atque eius rei fructum percipere, quem peto, ut optimi status auctor dicar et moriens ut feram mecum spem, mansura in vestigio suo fundamenta rei p. quae iecero" (Suet., Aug. 28.2).

Hay otra razón de peso por la que Agripa decidió no optar al triumphus ex Hispaniae: porque después del 29, el propio Augusto había renunciado a ese honor, o al menos teóricamente, en su formulación republicana tradicional. A cambio, desplegó el gran aparato propagandístico oficial, visible en monumentos y monedas, que le presentan - con una imagen minimizada, o falsamente humilde- como el triunfador por excelencia. Pero aún hay otra expresión más pura del monopolio del triunfo asimilado a su persona desde enero del 27: la incorporación a su onomástica personal el título vitalicio de Imperator, que es sinónimo de triumphator. En $R G 4.1$ el propio Augusto lo recuerda (appellatus sum vicies et semel imperator), y de ello se hacen eco dos historiadores, Tácito, Ann. 1.9.2, y Cass. Dio, 52.41.4. Hubiera sido o no Octavio-Augusto un buen militar, ese era el resultado, ser paradigma del general victorioso. Si no fue un excelente militar, sí habrá que reconocer que fue un genio de la política.

Por otro lado, en un pasaje de las mismas Res Gestae, deja bien asentado el principio de su máxima autoridad militar, reconocida y asumida tras Actium, y que incluye el derecho de arrogarse el futuro, cualquiera que sea la guerra, la responsabilidad suprema, el mérito final, de toda conquista: Iuravit in mea verba tota Italia sponte sua et me belli, quo vici ad Actium, ducem depoposcit. Iuraverunt in eadem verba provinciae Galliae, Hispaniae..., como se indica en $R G$ 25.2, y poco después en $R G$ 3.1.

En efecto -y por sus efectos-, toda la ideología augustea sobre conquistas y triunfos gira en torno al modelo de Actium. Esa victoria, mano con mano junto a Agripa, en el 31, fue el verdadero punto de inflexión del poder de Augusto, su verdadero fundamento militar; y el año 19, la victoria definitiva de Agripa sobre los pueblos del NO hispano supone su práctica culminación. Si el 31 Agripa no recibió un triumphus, tampoco habría de hacerlo el 19 por cerrar la guerra en Hispania. Tanto en Actium como en el caso de Hispania, Agripa mostró una generosidad inusitada, y quizás inapropiada, renunciando a ciertos derechos triunfales a favor del príncipe. Pero eran nuevos tiempos, de cambios radicales que exigían comprensión y grandeza, especialmente por quienes estaban siendo protagonistas de ese cambio constitucional que se había producido.

Sin embargo, y paradójicamente, ese mismo año 19 se hace inscribir en los Fasti Triumphales el nombre de L. Cornelius Balbus por sus victorias ex Africa (Fast. Cap. Desgrassi, p. 110). Parece, como se ha sugerido, que hay "cierta manipulación" inte-

immemorabilmente compenetrate fra di loro, fissate in un affresco senza gradazione prospettiche temporali, risolte nella realtà vincente". 
resada en la inscripción de los últimos triumphatores,${ }^{28}$ manipulación que se inscribe y hay que entender en el programa propagandístico del príncipe el año 19. Recuerda Barnes, en el mismo sentido, que tal manipulación política es también una especie de apropiación indebida, por cuanto "Augustus never again personally commanded an army on the field of battle". ${ }^{29} \mathrm{Y}$ en consecuencia "Hence his choice of victories for official commemoration should disclose something about his military policies, or at least about his propaganda. It thus occasions no surprise that he declined to take the imperatorial title for subsequent victories in Spain, even for those for which Agrippa was voted a triumph" (sc. Cass. Dio, 54.2.6).

El nombre de Balbo cierra los Fasti Triuphales "republicanos" (aunque stricto sensu ya no "republicanas" las escasas inscriptiones de triumphatores entre el $27 \mathrm{y}$ el 19). Es verdaderamente chocante esta inscripción que otorga a Balbo un honor que no recibe Agripa. Pero al mismo tiempo es magnífico comprobar cómo esa gratia de Augusto es concedida al último gran representante de los Balbos, "los confidentes de César", en frase afortunada de Rodríguez Neila, ahora "relegado" a la función honorabilísima, claro, de un proconsulado y un triumphus, pasando aquella condición de "confidente" a nuevo hombre fuerte de Roma al lado de Augusto: Agripa. Lo dice claramente Dión (54.12.2): tras rechazar Agripa los honores del triunfo, y luego de su expresión de fidelidad y amistad al príncipe, y tras dar muestras inequívocas de su magnanimidad con la ciudad de Roma y sus ciudadanos, Augusto otorgó a Agripa el primero y más grande honor, el de asociarlo al trono, "a su poder absoluto": ó $\delta \grave{\varepsilon}$

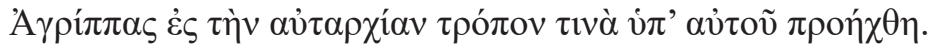

El análisis de los nombres inscritos en los últimos años de los Fasti Triumphales en relación con asuntos hispanos - del 36 al 26- nos ofrece un interesante retrato de los años convulsos del final de la República romana y los primeros años del Principado.

El periodo visto (ver tabla al final del presente estudio), se puede delimitar por grupos.

a) Desde el año 36 al 33. Los generales que actúan en la Península Ibérica son "antiguos cesarianos" o "nuevos octavianos". El año en que Octavio y Agripa vencen en Nauloco (el 36) va a ser el primero en que el poder de este dúo político-militar coloque, siempre con el beneplácito del Senado, "a sus hombres" en Hispania. Hemos visto que los triunfos que se celebran ex Hispania, según los Fasti, muchos de ellos no están plenamente justificados; pero había dos razones para facilitarlos: la primera, premiar a los hombres que habían luchado -aunque ciertamente con poca brillantez- junto a Octavio en la guerra contra Sexto Pompeyo, de modo que el "destino hispano" es un destino "digno" y susceptible de obtener éxitos militares negados en escenarios bélicos más duros; la segunda razón para la proliferación de triunfos en el periodo 36-33 (8 generales lo recibieron en este lapso) era la necesidad que tenía el Estado romano de "financiación exterior", que en el caso de los triunfos se sustanciaba en una aportación directa al tesoro mediante los spolia opima.

28 HiCKSON, 1991.

29 BARNES 1974, 219. 
b) Desde el año 31 al 29. El foco de interés político de Roma, y de sus principales actores en lid en este momento -Octavio, Marco Antonio- bascula claramente desde Occidente a Oriente. Los problemas de insurrección en Hispania debían ser mínimos. En Actium se dirime el futuro y el final de la República. De nuevo la victoria del tándem Octavio-Agripa, marca los acontecimientos. En el periodo 31-29 no se inscriben triumphus en los Fasti (no hay guerras externae), salvo la inclusión en el registro del año 29 de la victoria de Octavio contra Dalmatas. Ese año, como hemos visto, es crucial en el concepto de victoria y triunfo en Roma: Octavio va a celebrar su tiple triunfo en Dalmacia, Actio y Egipto. Augusto no va a celebrar más victorias - su colega Agripa no fue incluido en los Fasti Triumphatorum, ni antes ni después, cambiando ese honor por la recepción de los ornamenta triumphalia- y los registros de los Fasti se iban a clausurar definitivamente diez años más tarde, cuando se cerraran los frentes de guerra abiertos o reabiertos, en Hispania, Galia, Tracia y África.

c) Desde el año 28-26/25. El general Calvisio Sabino va a recoger en 28 el premio a los primeros combates exitosos en Hispania tras reabrir el frente de guerra, esta vez concentrado en el frente astur-cántabro. En este periodo vemos de nuevo una extraordinaria concentración de triumphus celebrados en Roma. Una razón práctica que explica este reflorecimiento de los triunfos fue, como de hecho había sido siempre, la necesidad de reforzar el erario público con los spolia (el "precio" o aportación que tenía que hacer el general victorioso a cambio de la honra del desfile triunfal en la urbe, sacado en todo caso del botín de guerra). En el periodo posterior al 27, en que Octavio, ya Augusto, recibe del Senado el poder proconsular maius por periodo de diez años, que le deja las manos libres para actuar en las provincias "imperiales", apenas vemos media docena de generales que celebran triunfos. Sus nombres indican que, de nuevo, los generales, ahora legados imperiales -rango equivalente a lo que pocos años antes eran legados-procónsules-son hombres “del nuevo régimen", con más experiencia en la política que en la guerra, pero que se habían mostrado antes fieles a Octavio, como Carrinas y Paetus (triunfan en el 28, ex Gallia), Valerius Mesalla (en el 27 ex Gallia) o Sex. Apuleius (en el 26, ex Hispania). Se produce un intercambio de favores: antiguos cónsules que aún buscan honores, u hombres que están potenciando sus carreras al calor del nuevo régimen. Ambos casos o razones se entienden bien en un momento de "asentamiento" del Principado en sus primeros años. Otro ejemplo es el de L. Cornelius Balbus, el joven, a quien se premia con un triunfo ex Africa el año 19. No se puede ignorar que éste es un premio a posteriori a la fidelidad y amistad de los Balbos de Gades hacia Julio César; un premio dado por Augusto, como para ir cerrando o abotonando con lucidez los últimos compromisos con los amigos republicanos.

d) El año 25. De la presencia de Augusto en Hispania. Es crucial en su vida. El episodio bélico hispano -en el que la participación directa del emperador es mínima-, pero le va a hacer reflexionar seriamente sobre su salud, siempre precaria; hasta el punto de que decide que en ese momento va a dejar de escribir sus Memorias (De sua vita), que venía redactando posiblemente desde diez años atrás.

e) Del 24 al 19. Se va a minimizar la celebración de los triunfos, que quedarán prácticamente, salvo excepción, como un privilegio del príncipe. Asentado ese principio no escrito, el vencedor definitivo de los cántabros, Agripa, no iba a celebrar ni a ser inscrito en los Fasti Triumphales. Pero ya se ha indicado que no era ningún desagravio. La humildad en este sentido de Agripa -que ya había percibido en primer lugar Octavio el año 36, en que Agripa rechazó un triunfo sobre los galos; declinatio que se repetiría en 
31, 19 y 14- y su sentido de Estado sólo pueden entenderse por la magnanimidad de este hombre que dejó todo el honor del triunfo militar a Octavio-Augusto.

Así, el cierre de la conquista del territorio hispano -igual que lo serían otros hechos bélicos residuales, pero importantes, de estos años, como la devolución por parte de los partos de los estandartes arrebatados a Craso, o la conclusión de los conflictos en Galia y África- serían incluidos como avales y justificación para que Augusto, ad maiorem glorium suam, desplegase un programa iconográfico gigantesco, por su simbolismo, en el Campo de Marte, en Roma, donde proyectó un arco monumental que sintetizaba - con la representación de una cuadriga- la teatralidad y el sentido del desfile triunfal, al tiempo que hacía inscribir en piedra los Fasti Triumphatorum, que debían ser encastrados, a modo pilastras, en el arco. Desde los tiempos antiguos -que llevó taimadamente "hasta Rómulo"- un romano de su época podía ver cómo todos los triunfos republicanos de los siglos pretéritos confluían en los triunfos augusteos. Augusto quiso presentarse así, de nuevo en un golpe de efecto político magistral, como un gran general sin serlo, como un Imperator con mayúsculas, y, del mismo modo, se predica como un nuevo conditor Romae, por su "nueva constitución política" y su hercúleo plan urbanístico. Y en ese proyecto de transformación de la República al Principado, esos años clave que van de 36 al 25, Hispania tuvo un papel capital en la afirmación del nuevo régimen.

\section{Tablas Resumen}

\begin{tabular}{|c|c|c|c|c|c|}
\hline \multirow[b]{2}{*}{ Año } & \multirow[b]{2}{*}{ Cos. } & \multicolumn{2}{|c|}{$\begin{array}{l}\text { VICTORIAS MILITARES SEGÚN } \\
\text { LOS FASTI TRIUMPHALES }\end{array}$} & \multirow{2}{*}{$\begin{array}{l}\text { Otras noticias } \\
\text { de interés } \\
\text { mencionadas } \\
\text { en los fasti }\end{array}$} & \multirow{2}{*}{$\begin{array}{c}\text { Momentos significativos } \\
\text { de la historia político- } \\
\text { militar romana }\end{array}$} \\
\hline & & EN HISPANIA & EN OTROS LUGARES & & \\
\hline 36 & $\begin{array}{l}\text { L. Gellius L. } \\
\text { f. (Poplicola) } \\
\text { M. Coc- } \\
\text { ceiu[s] } \\
\text { (Nerva) }\end{array}$ & $\begin{array}{l}\text { Cn. Domitius M. } \\
\text { f. M. n. Calvinus } \\
\text { procos. ex Hispania } \\
\text { XVI k. Sextil. } \\
\text { (Tr. Cap.) }\end{array}$ & $\begin{array}{l}\text { Imp. Caesar divi f. C. f. } \\
\text { II, IIvir r. p. c. II, ovans } \\
\text { ex Sicilia idibus Novem- } \\
\text { br. (Tr. Cap.) }\end{array}$ & & $\begin{array}{l}3 \text { de septiembre: Victoria } \\
\text { de Octavio, con la ayuda } \\
\text { decisiva de Agripa, en la } \\
\text { batalla de Nauloco, en } \\
\text { Sicilia, sobre la flota de } \\
\text { Sexto Pompeyo. } \\
\text { (Livio Per. CXXIX 2, } \\
\text { 4; Vel. II 79, 5; II 81, 3; } \\
\text { Suet. Aug. 9, 16; App. } \\
\text { BC V 118-122; Floro II } \\
\text { 18 (IV 8, 7); Cass. Dio } \\
\text { XLIX 8, 5-6; XLIX 9-10; } \\
\text { XLIX 11, 1; Eutr. VII 4; } \\
\text { Oros. VI 18, 29). }\end{array}$ \\
\hline 35 & $\begin{array}{l}\text { Sex. } \\
\text { Pomp(eius } \\
\text { Sex. f.) } \\
\text { L. Corni- } \\
\text { fi(cius L. f.) }\end{array}$ & & & & \\
\hline
\end{tabular}




\begin{tabular}{|c|c|c|c|c|c|}
\hline 34 & $\begin{array}{l}\text { M. Anton(ius } \\
\text { M. f.) II } \\
\text { L. Scribonius } \\
\text { (L. f. Libo) }\end{array}$ & $\begin{array}{l}\text { C. Norbanus C. f. } \\
\text { Flaccus procos. ex } \\
\text { Hispania IIII id[us } \\
\text { Oc]tobr. } \\
\text { (Tr. Cap.) }\end{array}$ & $\begin{array}{l}\text { T. Statilius T. f. Taurus } \\
\text { procos. ex Africa pridie } \\
\text { k. Iul. } \\
\text { (Tr. Cap.) } \\
\text { C. Sosius C. f. T. n. pro- } \\
\text { cos. ex Iudaea III nonas } \\
\text { Septembr. } \\
\text { (Tr. Cap.) } \\
\end{array}$ & $\begin{array}{l}\text { bellum Hillu- } \\
\text { ricum } \\
\text { (Ven.) }\end{array}$ & \\
\hline 33 & $\begin{array}{l}\text { Imp. Caesar } \\
\text { (divi f.) II } \\
\text { L. Volcacius } \\
\text { (L. f. Tullus) }\end{array}$ & $\begin{array}{l}\text { L. Marcius Philipus } \\
\text { ex Hispania V k. } \\
\text { Mai. triumphavit } \\
\text { palmam dedit. } \\
\text { (Tr. Cap.) } \\
\text { Ap. Claudius Pulcer } \\
\text { ex Hispania k. Iun. } \\
\text { triumphavit palmam } \\
\text { dedit. } \\
\text { (Tr. Cap.) } \\
\end{array}$ & $\begin{array}{l}\text { L. Cornificius ex Africa } \\
\text { III non. Dec. triumphavit } \\
\text { palmam dedit. } \\
\text { (Tr. Cap.) }\end{array}$ & & $\begin{array}{l}\text { Segundo consulado de } \\
\text { Octavio. }\end{array}$ \\
\hline 32 & $\begin{array}{l}\text { Cn. Domitius } \\
\text { (L.f. Aheno- } \\
\text { barbus) } \\
\text { C. Sossius } \\
\text { (C.f.) } \\
\end{array}$ & & & $\begin{array}{l}\text { bellum } \\
\text { Acties, } \\
\text { class[iar.] } \\
\text { cum Antonio } \\
\text { (Amit.) } \\
\end{array}$ & \\
\hline 31 & $\begin{array}{l}\text { Imp. Caes. } \\
\text { Divi f. III } \\
\text { M. Valerius } \\
\text { (M.f.) Mes- } \\
\text { sal(la) }\end{array}$ & & & $\begin{array}{l}\text { bellum Acti } \\
(\text { Ven. })\end{array}$ & $\begin{array}{l}\text { Tercer consulado de } \\
\text { Octavio. } \\
\mathbf{2} \text { de septiembre: Batalla } \\
\text { de Actio, en el golfo de } \\
\text { Ambracia. Octavio, con la } \\
\text { ayuda de Agripa, pone en } \\
\text { fuga a la flota de Antonio } \\
\text { y Cleopatra. } \\
\text { (Aug. RG 25; Livio Per. } \\
\text { CXXXIII 1; Vel. II 84, } \\
\text { 1-2; II 85, 1-6; Plin. NH } \\
\text { VII 45, 148; Jos. Bell. Iud. } \\
\text { I 15 (I 386); Ant. XV 161; } \\
\text { Contr. Ap. II 5, 59; Plut. } \\
\text { Ant. 63-68, 71; Suet. Aug. } \\
\text { 9, 17, 18; Floro II 21 (IV } \\
\text { 11, 4-8); Cass. Dio L 14, } \\
\text { 3-4; L 15-35; LI 1, 1, 4; } \\
\text { Eutr. VII 7; Oros. VI 19, } \\
\text { 8-12) } \\
\end{array}$ \\
\hline 30 & $\begin{array}{l}\text { Imp. Caes. } \\
\text { Divi f. IV } \\
\text { M. Licinius } \\
\text { (M.f.) Cras- } \\
\text { sus }\end{array}$ & & & $\begin{array}{l}\text { bell[um clas- } \\
\text { sia]r. confect. } \\
\text { (Amit.) } \\
\text { bellum Alex- } \\
\text { andreae } \\
(\text { Ven.) }\end{array}$ & $\begin{array}{l}\text { Cuarto consulado de } \\
\text { Octavio. Suicidio de } \\
\text { Antonio. } \\
\mathbf{1} \text { de agosto: Toma de } \\
\text { Alejandría y suicidio de } \\
\text { Cleopatra. } \\
\text { Egipto, "provincia" } \\
\text { romana. } \\
\text { Concesión a Octavio de } \\
\text { la tribunicia potestas de } \\
\text { por vida. } \\
\end{array}$ \\
\hline
\end{tabular}

${ }^{30}$ En Ven. se omite el nombre de M. Antonius, poniendo en su lugar, como consul ordinarius a L. Sempronius. 


\begin{tabular}{|c|c|c|c|c|c|}
\hline 29 & $\begin{array}{l}\text { Imp. Caes. } \\
\text { Divi f. V } \\
\text { Sex. } \\
\text { Appuleius } \\
\text { (Sex.f.) }\end{array}$ & & $\begin{array}{l}\text { Imp. Caesar de Dalma- } \\
\text { tiis eid. Sext. triumph. } \\
\text { palman dedit. } \\
\text { (Tr. Barb.) } \\
\\
\text { Imp. Caesar ex A[egy] } \\
\text { pto XIIX k. Sept. trium- } \\
\text { phavit. } \\
\text { (Tr. Barb.) }\end{array}$ & & \begin{tabular}{|l} 
Quinto consulado de \\
Octavio. \\
13-15 de agosto: celebra- \\
ción del triple triunfo de \\
Octavio, por las victorias \\
en Dalmacia, Actio y \\
Egipto. $($ RG 4; Suet. Aug. \\
22; Virg. Aen. 8, 714).
\end{tabular} \\
\hline 28 & $\begin{array}{l}\text { Imp. Caes. } \\
\text { Divi f. VI } \\
\text { M. Agrippa } \\
\text { (L.f.) II }\end{array}$ & $\begin{array}{l}\text { [C. C]alv[is] } \\
\text { ius [S]abinus ex } \\
\text { Hispania VII k. Iun. } \\
\text { triumphavit palmam } \\
\text { dedit. } \\
\text { (Tr. Barb.) }\end{array}$ & $\begin{array}{l}\text { [C. Carr]inas ex [G] } \\
\text { al[1]is prid. eid. Iul.] } \\
\text { triumph. palmam dedit. } \\
\text { (Tr. Barb.) } \\
\\
\text { L. Autronius P. f. L. n. } \\
\text { Paetus procos. ex Africa } \\
\text { XVII k. Septemb[r.] } \\
\text { (Tr. Cap.) }\end{array}$ & \begin{tabular}{l}
\multicolumn{1}{c}{ idem } \\
(cos.) censo- \\
ria potest(ate) \\
lustrum \\
fecer(unt). \\
$\quad$ (Ven.)
\end{tabular} & $\begin{array}{l}\text { Sexto consulado de } \\
\text { Octavio. }\end{array}$ \\
\hline 27 & $\begin{array}{l}\text { Imp. Caes. } \\
\text { Divi f. VII } \\
\text { M. Agrippa } \\
\text { (L.f.) III }\end{array}$ & & $\begin{array}{l}\text { M. Licinius M.f. M.n. } \\
\text { Crassus procos. ex } \\
\text { Thraecia et Geteis IV } \\
\text { non. Iul. } \\
\text { (Tr. Cap.) } \\
\text { M. Valerius M.f. M.n. } \\
\text { Mesalla Corvinus pro- } \\
\text { cos. ex Gallia VII k. Oct. } \\
\text { (Tr. Cap.) }\end{array}$ & $\begin{array}{l}\text { [Imp. Caesar } \\
\text { vale]tudin(e) } \\
\text { impeditus } \\
\text { fuit. } \\
\text { (Lat.) }\end{array}$ & $\begin{array}{l}\text { Séptimo consulado de } \\
\text { Octavio. } \\
\mathbf{1 3} \text { de enero: Octavio } \\
\text { devuelve al Senado los } \\
\text { poderes magistraturales. } \\
\mathbf{1 6} \text { de enero: Octavio ob- } \\
\text { tiene del Senado el título } \\
\text { de Augusto y el imperium } \\
\text { proconsulare maius por } \\
\text { plazo de diez años, que le } \\
\text { da las manos libres para } \\
\text { intervenir militarmente en } \\
\text { las provincias a él asigna- } \\
\text { das. División del Imperio } \\
\text { en provincias imperiales } \\
\text { y senatoriales. } \\
\text { Desde este momento el } \\
\text { nombre oficial es Impera- } \\
\text { tor Caesar Augustus. }\end{array}$ \\
\hline 26 & \begin{tabular}{|l} 
Imp. Caes. \\
Divi f. VIII \\
T. Statilius \\
Taurus (T.f.) \\
Taurus II
\end{tabular} & $\begin{array}{l}\text { Sex. Appuleius Sex. } \\
\text { f. Sex. n. procos. } \\
\text { ex Hispania VII k. } \\
\text { Febr. } \\
\text { (Tr. Cap.) }\end{array}$ & & $\begin{array}{l}\text { [Imp. Caesar } \\
\text { in] Hispania } \\
\text { fuit. } \\
\text { (Lat.) }\end{array}$ & $\begin{array}{l}\text { Octavo consulado de } \\
\text { Augusto. }\end{array}$ \\
\hline 25 & $\begin{array}{l}\text { Imp. Caes. } \\
\text { Divi f. VIIII } \\
\text { M. Iunius } \\
\text { (M.f.) Sila- } \\
\text { nus }\end{array}$ & $\begin{array}{l}{[\text { De este año en }} \\
\text { adelante no hay } \\
\text { más triunfos ex } \\
\text { Hispania] }\end{array}$ & & $\begin{array}{l}\text { [Imp. Caes]ar } \\
\text { in Hispania } \\
\text { fuit. } \\
\text { (Lat. ) }\end{array}$ & $\begin{array}{l}\text { Noveno consulado de } \\
\text { Augusto. }\end{array}$ \\
\hline
\end{tabular}




\section{SigLAS}

Amit. $=$ Fasti Amiternini (del 63 al 28 a.C.) = CIL IX 4190-4191; CIL I² p.61; Inscr.It. XIII 1, p.169 ss.

$\mathrm{CIL}=$ Corpus Inscriptionum Latinarum .

$\mathrm{ILS}=$ Inscriptiones Latinae Selectae (H. Dessau).

Lat. $=$ Fasti Feriarum Latinarum. CIL I²; Inscr.It. XIII 1 ad locum.

$R G=$ Res Gestae Divi Augusti.

Tr. Barb. = Fasti Triumphales Barberini. CIL I²; Inscr.It. XIII 1 ad locum.

Tr. Cap. $=$ Fasti Triumphales Capitolini. (A. Degrassi, Fasti Capitolini, Torino 1954).

Suppl. Ital. XIII/1 = A. DegRassI, Inscriptiones Italiae, vol. XIII, fasc. 1, Roma 1947.

Ven. $=$ Fasti Venusini (ILS 6123; V. EHRENBERG - A.H.M. Jones, Documents illustrating the Reigns of Augustus \& Tiberius, Oxford University Press, $\left.1963\left(2^{\mathrm{a}}\right), \mathrm{n}^{\mathrm{o}} 323\right)$.

\begin{tabular}{|c|c|c|c|}
\hline \multicolumn{4}{|c|}{$\begin{array}{c}\text { GOBERNADORES DE HISPANIA EN 27-17 A.C. } \\
\text { Según R. Syme, 1934, 315-316; G. ALFÖLDy, Fast. Hisp. 1969, 303-304, } 307 .\end{array}$} \\
\hline & Tarraconensis (Hispania Citerior) & Lusitania (Hispania Ulterior) & \\
\hline $27-24$ & $\begin{array}{l}\text { C. Antistius Vetus (cos. 30). Flor. } 2 . \\
\text { 33.51; Oros. 6. 21.6-7; Cass. Dio 53.25.7- } \\
\text { 8; Vell. 2.90.4. }\end{array}$ & \multirow[b]{2}{*}{$\begin{array}{l}\text { P. Carisius (quizás nunca cónsul). } \\
\text { Flor. 2.33.55-8; Oros. 6.21.10; Cass. } \\
\text { Dio 53.25.8; 54.5.1-2. }\end{array}$} & \multirow[b]{2}{*}{$26 / 25-22$} \\
\hline $24-22$ & $\begin{array}{l}\text { L. Aemilius (Paullus Lepidus, cos. 34). } \\
\text { Cass. Dio 53.29.1. O bien: } \\
\text { L. (Aelius) Lamia. Cassiod. Chron. ann. } \\
730 \text {. }\end{array}$ & & \\
\hline $22-19$ & $\begin{array}{l}\text { C. Furnius (cos. } 17 \text { B.C.). Flor. 2.33. 51; } \\
\text { Oros. 6.21.6-7; Cass. Dio 54.5.1-2. }\end{array}$ & & \\
\hline $19-17$ & $\begin{array}{l}\text { P. Silius Nerva (cos. 20. Vell. 2.90.4; CIL } \\
\text { II } 3414 .\end{array}$ & $\begin{array}{l}\text { L. Sestius Quirinalis Albinianus } \\
\text { (cos. 23) }\end{array}$ & $22 ?-19 ?$ \\
\hline
\end{tabular}

\section{Bibliografía}

Aja Sánchez, J. R. - Cisneros Cunchillos, M. - Ramírez Sádaba. J. L. (eds.) (2008): Los cántabros en la Antigüedad, Santander.

AlföLdy, G. (1969): Fasti Hispanienses, Wiesbaden.

Amela Valverde, L.

(2006): "Triunfos en Hispania a finales de la República", Iberia 9, 49-61.

(2009): Hispania durante el Segundo Triunvirato (44 - 30 a.C.), Madrid. (=Aquila legionis 11, número monográfico).

Auliard, C. (2001): Victoires et triomphes à Rome, Paris. 
Badian, E. (1984): Foreign Clientelae (264-70) BC., Oxford.

BARINI, C. (1952): Triumphalia. Imprese ed onori militari durante l'impero Romano, Turin.

BARneS, T. D. (1974): “The victories of Augustus", Journal of Roman Studies 64, 21-26.

BASTIEN, J.-L. (2007): Le triomphe romain et son utilisation politique à Rome aux trois derniers siècles de la république, Roma.

BEARD, M.

(2008): “Trionfi: rappresentazione o fizzione?”, [en] La Rocca, E. - Tortorella, S. et alii (eds.) Trionfi romani, Milano, 72-75.

(2009): El triunfo romano: una historia de Roma a través de la celebración de sus victorias, Barcelona.

Brancati, A. (1963): Augusto e la guerra di Spagna, Urbino.

BrigmanN, K. - SchÄFER, TH. (2002): Augustus und die Begründung des römischen Kaisertums, Berlin.

Brigmann, K. (2008): Augusto, Barcelona.

Brougthon, T. R. S. (1952): The Magistrates of Roman Republic, vol. II, 99 BC-31 BC, New York (with suppl. New York, 1960).

Cagnat, R. (1906): "Note sur une inscription de Carthage relative a Sex. Appuleius", CRAI, 470-478.

Canali, L. (1982): Cesare Ottaviano Augusto - Res Gestae Divi Augusti, Roma 1982.

Cieri Via, C. (2008), "Il trionfo antico fra pathos ed ethos", [en] La Rocca, E. - Tortorella, S. et alii, Trionfi romani, Milano, 10-18.

Cortés Copete, J. M. (2011): Dión Casio, Historia Romana, libros L-LX, Madrid.

DEgrassi, A.

(1947): Inscriptiones Italiae, vol. XIII, fasc. 1, Roma.

(1954): Fasti Capitolini, Torino.

Del Cerro Calderón, G. (2010): Testamento de Augusto - Monumentum Ancyranum, Madrid.

Ehrenberg, V. - Jones, A. H. M. Jones (1963-2a), Documents illustrating the Reigns of Augustus \& Tiberius, Oxford.

Evans, R. J. (1987): "Norbani Flacci. The Consuls of 38 and 24 B.C.”, Historia 36, 121-128.

FORNI, G. (1970): “L'occupazione militare romane nella Spagna nord-occidentale: analogie e parallele”, en Legio VII Gemina, León, 205-225.

Freyburger-Galland, M.-L. (2009): “Res Publica Restituta chez Dion Cassius", [en] F. Hurlet - B. Mineo (eds.), Le Principat d'Auguste. Realités et répresentations du pouvoir. Autour de la Res publica Restituta, Rennes, 325-341.

Gagé, J. (1935) : Res Gestae Divi Augusti. Paris.

Galinsky, K. (2012): Augustus, Introduction to the Life of an Emperor, Cambridge.

Giroire, C. (2013): “Augusto e le provincie”, [en] E. La Rocca (ed.), AvGVSTo, Milano, 289291.

Giustozzi, N. (2006): Museos Capitolinos. Guía, Roma.

González Salinero, R. (2009): "Recensión a Beard (2009)”, Aquila legionis 12, 152-158.

Gratacós Freixas, E. (2002): “Cn. Domitius Calvinus”, GN 147, 15-17. 
Groag, E - Stein, A. (1936 ss.): Prosopographia Imperii Romani. Saec. I. II. III, Berlin (citado $\left.P I R^{2}\right)$.

Hickson, F. V. (1991): “Augustus triumphator: manipulation of the triumphal themes in the political program of Augustus", Latomus 50, 125-138.

Huort Lange, C. (2009): Res Publica Constituta. Actium, Apollo and the Accomplishment of the Triunviral Assignment, Leiden-Boston.

Horrent, J. (1953): “Nota sobre el desarrollo de la Guerra Cántabra del año 26 a.C.”, Emerita 21, 279-290.

Itgenshorst, T. (2004): “Augustus und der republikanische Triumph: Triumphalfasten und summi viri-Galerie als Instrumente der imperialen Machtsicherun”, Hermes, 132/4, 436458.

Itgenshorst, T. (2005): Tota illa pompa. Der Triumph in der römischen Republik, Gottingen.

Jones, R. F. J. (1976): “The Roman military occupation of North-West Spain”, Journal of Roman Studies 66, 45-66.

KLEINER, F. S. (1988): “The Arch in Honor of C. Octavius and the Fathers of Augustus", Historia: Zeitschrift für Alte Geschichte 37, 347-357.

KüNZ, E. (1988): Der römische Triumph. Siegesfeiern im antiken Rom, München.

La Rocca, E. - Tortorella, S. et alii (2008): Trionfi romani, Roma.

LA Rocca, E. (ed.) (2013): AVGVSTO, Milano.

Lacey, W. K. (1974): “Octavian in the Senate, January 27 B.C.”, The Journal of Roman Studies $64,176-184$.

Lo Monaco, A. (2008): "In processione al Circo Annalisa Lo Monaco”, [en] La Rocca, E. Tortorella, S. et alii (eds.), Trionfi romani, Roma 76-83.

Magie, D. (1929): “Augustus’ war in Spain”, Classical Philology 15, 323-339.

MaIUro, M. (2008): “Il trionfo dalla Repubblica a Costantino: regole, ruoli e pratiche”, [en] La Rocca, E. - Tortorella, S. et alii (ed.), Trionfi romani, Roma, 20-29.

Montenegro Duque, A.

(1978): “Augusto e Hispania”, [en] Historia de España Antigua II. Hispania Romana, Madrid, 253-285.

(1982): “Augusto en Hispania y las guerras cántabras", [en] Historia de España, dirigida (en su primera edición) por Menéndez Pidal, Madrid, 169-192.

PAIS, E. (1920): Fasti Triumphales Populi Romani, I-II, Roma.

Peralta Labrador, J. (2000): Los cántabros antes de Roma, Madrid.

PEREA YÉBENES, S.

(2002-2003): “Aclamaciones militares y poder político en Roma”, Memorias de Historia Antigua 23-24, 141-176.

(2008): "Un capítulo de la lucha Augusto contra los bárbaros: el bellum cantabricum. Los generales y sus efectivos", [en] J. R. Aja Sánchez - M. Cisneros Cunchillos - J. L. Ramírez Sádaba (eds.), Los cántabros en la Antigüedad, Santander, 120-131.

(2013): “Octavianus - Neptunus", Cadmo. Revista de História da Universidad de Lisboa 23, 2013, 147-167. 
(2015): "Los inicios de César (Octavio) como jefe militar: el año 44, de Apolonia a Roma,

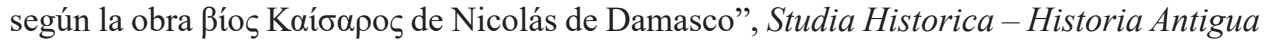
33, 97-133.

Pollini, J. (1986): "Ahenobarbi, Appuleii and Some Others on the Ara Pacis", American Journal of Archaeology 90, 1986, 453-460.

Presicce, C. P. (2013): “L'Augusto di Prima Porta 150 anni dopo la scoperta”, [en] E. La Rocca (ed.), AVGVSTO, Milano, 118-129.

RAMAGE, E. S.

(1998): “Augustus' Propaganda in Spain”, Klio 80, 434-490.

(1987): The Nature and Purpose of Augustus "Res Gestae”, Stuttgart.

ReInHold, M. (1933): Marcus Agrippa. A Biography, Geneva-New York.

Rich, J. (2009): “Cantabrian closure: Augustus' Spanish War and the ending of his Memoirs", [en] Chr. Smith - A. Powell (eds.), The lost memoirs of Augustus and the development of Roman autobiography, Swansea, Wales, 145-172.

RodDaz, J.-M.

(1984): Marcus Agrippa, Paris.

(1993): “Agripa y la Península Ibérica”, Anas 6, 111-126.

Rodríguez Colmenero, A. (1978): Augusto e Hispania, Bilbao.

Rodríguez Neila, J. F. (1992-2ª): Confidentes de César. Los Balbos de Cádiz, Madrid.

Roger, D. (2013): “Ottaviano conquista il potere assoluto”, [en] E. La Rocca (ed.), AVGVSTO, Milano, 141-152.

Roldán Hervás, J. M. - Wulf Alonso, F. (2001): Historia de España, III. Historia Antigua. Citerior y Ulterior. Las provincias hispanas en la época republicana, Madrid.

RÜPKE, J. (2006): “Triumphator and Ancestor Rituals between Symbolic Anthropology and Magic", Numen 53, 251-289.

SALINAS DE Frías, M.

(1996): El gobierno de las provincias hispanas durante la República romana (218-27 a.C.), Salamanca.

(1986): La organización tribal de los vettones, Salamanca.

Santos Yanguas, N. (1982): "La conquista romana del N.O. de la Península Ibérica", Latomus 41, 5-49.

SCHIESARO, A. (2008): "La processione trionfale come spettacolo per il popolo romano. Trionfi antichi, spettacoli moderni”, [en] La Rocca, E. - Tortorella, S. et alii (eds.), Trionfi roma$n i$, Roma, 34-55.

Schmitthenner, W. (1962): “Augustus'spanischer Feldzug und der Kampf um den Prinzipat”, Historia: Zeitschrift für Alte Geschichte 11/1, 29-85.

Schulten, A. (1962): Los cántabros y astures y su lucha con Roma, Madrid.

Schulten, A. (ed.) (1940): Fontes Hispaniae Antiquae. V. Las guerras de 72 a 19 a.C., Barcelona.

Spalinger, A. - Armstrong, J. (2013): Rituals of Triumph in the Mediterranean World, London - Leiden.

Sweeney, J. M. (1978): “The Career of Cn. Domitius Calvinus”, AncW 1, 179-185. 
Syme, R. (1934): “The Spanish War of Augustus (26-25 B. C.)", American Journal of Philology 55, 293-317.

TARPIN, M. (2009): “Le triomphe d'Auguste: héritage de la République ou révolution?”, [en] F. Hurlet - B. Mineo (eds.), Le Principat d'Auguste. Realités et répresentations du pouvoir. Autour de la Res publica Restituta, Rennes, 129-142.

ZANker, P. (1992): Augusto y el poder de las imágenes, Madrid. 